\title{
The Decomposition of Somali Nouns
}

\author{
Nicola Lampitelli \\ Université Paris Diderot-Paris 7 \\ nicolalampitelli@gmail.com
}

\begin{abstract}
The goal of this paper is to understand the internal organization of Somali nouns. More precisely, I propose an analysis of the inflectional markers, i.e. the exponents of gender, number and syntactic case. Within a syntactic approach to noun formation, I show that a list of basic exponents can be reached throughout the phonological deconstruction of the surface forms. In addition, I argue that each phonological exponent corresponds to a unique morpho-syntactic category. On a more general level, the analysis depicted illustrates the behavior and the formation of basic and non-derived nouns in Somali, regardless the notion of "noun class".
\end{abstract}

\section{Keywords}

phonological exponent - nominal architecture - spell-out - noun class - inflectional marker - Somali - Cushitic

1

Introduction

In Somali, each basic and non-derived noun fits one of five inflectional classes (Andrzejewski, 1964; Banti, 1988; Hyman, 1981; Orwin, 1995; Puglielli \& Siyaad, 1984; Saeed, 1993). An inflectional class is defined on the basis of the following three parameters: (i) the position of a tonal accent, (ii) the gender in the sg. and in the pl. and (iii) the way plural is formed. Examples below illustrate this situation: ${ }^{1}$

\footnotetext{
1 Standard Somali spelling, which uses the Latin alphabet, is adopted throughout the paper. In
} a few cases, particular spelling conventions are adopted and the following correspondences

(C) KONINKLIJKE BRILL NV, LEIDEN, 2014 | DOI: 10.1163/18776930-00500004 
(1) a. naág F sg. vs. naagó M pl. 'woman/women', class 1

b. albáab M sg. vs. albaabbó F pl. 'door(s)', class 2

c. ílik M sg. vs. ilkó $\mathrm{M} \mathrm{pl}$. 'tooth/teeth', class 3

d. míis $\mathrm{M}$ sg. vs. miisás $\mathrm{M}$ pl. 'table(s), class 4 ,

e. mádax M sg. vs. madáx F pl. 'head(s)', class 5

In this paper, I propose an analysis of the system depicted in (1) and I propose an underlying structure for the noun in Somali. Two crucial hypotheses will be put forward, building on Godon (1998). First, a unique plural marker is postulated for Somali nouns; secondly, feminine nouns are marked by an underlying syllable, which is detectable at surface level as a tonal accent shift. Also, it is shown that the notion of "noun class" is redundant, as each noun is the result of the composition of basic morpho-phonological objects.

The analysis proposed in this work is couched within the theoretical framework known as the generalized CV-hypothesis (cf. Lowenstamm, 1996; Scheer, 2004), and the more general Autosegmental Phonology program (cf. Goldsmith, 1978; McCarthy, 1981). In addition, the ideas presented in this paper are consistent with a syntactic approach to word formation, such as Distributed Morphology (henceforth DM; Halle \& Marantz, 1993; Embick \& Halle, 2005; Embick \& Noyer, 2007; Marantz, 1997; Marantz, 2001; Marantz, 2008). Following a program initiated by Bendjaballah (2003), I argue for a strict one-to-one relation between the form of an exponent and its morpho-syntactic function. This hypothesis entails a revision of the realizational procedures proposed by DM.

The paper is structured as follows. In section 2, I present the data in a detailed fashion. Sections 3 and 4 contain the analysis: the former introduces the main hypotheses on the exponents of each morpheme, whereas the latter presents the syntactic derivation of the nouns. Finally, section 5 concludes.

2

The Data

According to Hyman (1981), each Somali noun bears a tonal accent (henceforth TA), which is associated either to the last or to the penultimate vowel..$^{2}$ It

with the IPA notation hold: $\langle\mathrm{sh}\rangle / \mathrm{d} /,\langle\mathrm{kh}\rangle / \mathrm{x} /,\langle\mathrm{dh}\rangle / \mathrm{d} /,\langle\mathrm{x}\rangle / \mathrm{h} /,\langle\mathrm{c}\rangle / \mathrm{S} /,\left\langle{ }^{\prime}\right\rangle / \mathrm{P} /,\langle\mathrm{j}\rangle / \mathrm{d} \hat{\mathrm{z}} /$ and $\langle\mathrm{y}\rangle / \mathrm{j} /$. In addition to standard conventions, tonal accent is marked only when it occurs.

2 Long vowels count as two units, as the following contrasts demonstrate: háan 'throat' vs. haán 'water container', qáan 'young camels' vs. qaán 'debt', ceesáan 'male goat' vs. ceesaán 'female goat'. Cf. Puglielli \& Siyaad (1984:55-56) for other examples.

BAALL 5 (2013) 118-159 
consists of a high pitch, and it contrasts either with a low pitch or the absence of pitch. It is then assumed that the peculiar characteristic of a noun is the presence of a given tonal accent, regardless of the height of the pitch. ${ }^{3}$

In addition, Somali has three syntactic cases, nominative (NOM), genitive (GEN), and absolutive (ABS), and a vocative case which will not be treated in the present study. The ABS is considered to be the default case, and is used when a noun is either a focussed subject or a direct object (either focussed or not) (cf. Saeed, 1993: 138). ${ }^{4}$ In fact, knowing an ABS form for a given noun allows the prediction of the form of all other cases.

In this paper, a classification based on both Saeed (1993, 1999) and Orwin (1995) is adopted. ${ }^{5}$ The reason of such a choice is twofold: on the one hand, both Saeed and Orwin propose a classification where nouns sharing the same plural formation strategy are put in the same group; on the other side, they consider the ABS as the basic case, and they both take into account only the ABS in determining their classes. Interestingly, within a given class, the TA is associated to the same position. ${ }^{6}$

The table containing the forms of each class is given below, and a table with examples follows:

3 Cf. Armstrong (1934) for more details on tonal pitch in Somali.

4 Banti (1988) and Puglielli \& Siyaad (1984) had already noticed that the absolutive is the default case. More recently, Frascarelli \& Puglielli $(2005,2007 \mathrm{~b}, \mathrm{a})$ proposed that the ABS marking on the subject follows from the predicative status of the focussed DP in a Small Clause configuration. In particular, Frascarelli \& Puglielli (2005:14) claim that "in Somali [DP's] are not located in situ, or rather, they cannot be located in situ because they never have an argument role".

5 Despite Saeed's (1999) and Orwin's (1995) classifications, I do not include what would have been classes 6 and 7 , respectively. These are characterized by suffixed nouns in the sg.: the former includes feminine nouns ending in -o (cf. wáddo 'road'), whereas the latter includes masculine nouns ending in -e (cf. báre 'teacher'). Both have a specific plural suffix which is added to the singular form (cf. waddoóyin 'roads' and barayaal 'teachers'). According to Puglielli \& Siyaad (1984) and later Lecarme (2002), these nouns are all derived, thus contrasting with the other classes. For this reason, I will not be concerned with them in this paper.

6 It is important to emphasize that subclass 1.b belongs to class 3 in Orwin's (1995) terms, whereas Saeed (1993) puts it with class 1. Saeed's system has a practical advantage, as 1.b nouns are feminine like those in 1.a. Moreover, class 3 plurals do not display gender polarity; nouns in 1.b do. 
TABLE $1 \quad$ Inflectional classes 7

\begin{tabular}{|c|c|c|c|c|c|c|}
\hline & Singular form & Gender & TA & Plural form & Gender & TA \\
\hline 1 & $*_{-0}$ & $\mathrm{~F}+$ & $\mathrm{v} \underline{\mathrm{v}} \#$ & -ó & M & $\mathrm{v} \underline{\mathrm{v}} \#$ \\
\hline 2 & ${ }^{*}$-e & $\mathrm{M}+$ & $\underline{\mathrm{v}} \mathrm{v} \#$ & -Có (-yó) & $\mathrm{F}$ & $\mathrm{v} \underline{\mathrm{v}} \#$ \\
\hline 3 & $\mathrm{C}(\mathrm{V}) \mathrm{V}_{i} \mathrm{CV}_{i} \mathrm{C}$ & $\mathrm{M}$ & $\underline{\mathrm{v}} \mathrm{v} \#$ & $\mathrm{C}(\mathrm{V})$ VCCó & M & $\mathrm{v} \underline{\mathrm{v}} \#$ \\
\hline 4 & $\mathrm{C}(\mathrm{V}) \mathrm{VC}$ & $\mathrm{M}$ & $\underline{\mathrm{v}}(\mathrm{v}) \#$ & C(V)VCáC & M & $\mathrm{v} \underline{\mathrm{v}} \#$ \\
\hline 5 & ${ }^{*} \mathrm{CVC}$ & $\mathrm{M}$ & $\underline{\mathrm{v}} \mathrm{v} \#$ & & $\mathrm{~F}$ & $\mathrm{v} \underline{\mathrm{v}} \#$ \\
\hline
\end{tabular}

TABLE 2 Examples 8

\begin{tabular}{|c|c|c|c|c|c|c|c|}
\hline & $\begin{array}{l}\text { Singular } \\
\text { bare } \mathrm{N}\end{array}$ & $\mathrm{N}+$ det & Gender & $\begin{array}{l}\text { Plural } \\
\text { bare N }\end{array}$ & $\mathrm{N}+$ det & Gender & \\
\hline $\begin{array}{r}1 . a \\
. b\end{array}$ & $\begin{array}{l}\text { naág } \\
\text { galáb }\end{array}$ & $\begin{array}{l}\text { naágta } \\
\text { galábta }\end{array}$ & $\mathrm{F}+$ & $\begin{array}{l}\text { naagó } \\
\text { galbó }\end{array}$ & $\begin{array}{l}\text { naagáha } \\
\text { galbáha }\end{array}$ & M & $\begin{array}{l}\text { 'woman' } \\
\text { 'afternoon' }\end{array}$ \\
\hline $\begin{array}{r}2 . a \\
. b\end{array}$ & $\begin{array}{l}\text { albáab } \\
\text { daríiq }\end{array}$ & $\begin{array}{l}\text { albáabka } \\
\text { daríiqa }\end{array}$ & $\mathrm{M}+$ & $\begin{array}{l}\text { albaabbó } \\
\text { dariiqyó }\end{array}$ & $\begin{array}{l}\text { albaabbáda } \\
\text { dariiqyáda }\end{array}$ & F & $\begin{array}{l}\text { 'door' } \\
\text { 'road' }\end{array}$ \\
\hline 3 & ílik & éligga & M & ilkó & ilkáha & M & 'tooth' \\
\hline 4 & miis & múiska & M & miisás & miisáska & M & 'table' \\
\hline 5 & mádax & mádaxa & M & madáx & madáxda & F & 'head' \\
\hline
\end{tabular}

7 In the first column, the label 'form' indicates the phonological restriction(s) applying to that particular class, whereas on the third column, the label 'TA' shows the position of the TA with respect to the vowels. In the second column, ' $\mathrm{F}+$ ' and 'M+' respectively mean that feminine and masculine nouns are the overwhelming majority in that particular class.

8 The columns labelled 'bare N' contain the isolated forms of nouns, whereas the ones labelled 'N+det' show each noun when suffixed with the determiner /ka/ (M) or /ta/ (F). The latter situation is referred to as the "premodifier form" configuration, and is formed whenever the noun is not the last element in the NP (cf. Orwin, 1995:40-41). The last element can be a determiner, an adjective, etc. According to Saeed (1993), Orwin (1995) and Puglielli \& Siyaad (1984), when a noun is in the premodifier form, it is marked by the absolutive accentual pattern, regardless of the actual syntactic position of the NP it belongs to. Throughout the rest of the paper, we will be only marginally concerned with this syntactic position. Note, however, that the determiner undergoes a few phonological modifications, depending on the final segment of the stem. These have been shown by Saeed (1993:161-163) and later analyzed by Barillot (2002):

BAALL 5 (2013) 118-159 
Gray cells in both tables indicate the classes displaying change in gender in the plural. These are 1,2 , and 5 . This phenomenon is referred to as the gender polarity (cf. Lecarme, 2002). It is not per se strange, as similar and related cases exist in French, Italian, Arabic, etc. ${ }^{9}$ However, in Somali every noun can, in principle, be pluralized by changing the gender of its singular form, except for the ones in declensions 3 and 4 . When gender polarity occurs, it is always accompanied by the change of the position of the TA. The change in gender in the plural is thus linked to the TA, but exactly how remains to be determined.

Class 1 includes all those nouns whose singular form does not end in -o, and whose plural ends in $-o$ and is masculine. The overwhelming majority of these singular nouns are feminine, and the TA is always on the final vowel. Nouns in 1.b behave in a slightly different way with respect to the second vowel of their stem (henceforth $\mathrm{V}_{2}$ ): this vowel alternates with zero in the plural. In addition, class 2 includes nouns whose singular form does not end in $-e$, and whose plural ends in - $o$ and is feminine. In the singular, these are overwhelmingly masculine, and the TA is always on the penultimate vowel. ${ }^{10}$ As can be seen in table 2, nouns in 2.a are characterized by the gemination of the last consonant in the plural stem. On the other hand, if the last consonant of the stem is a guttural, $\mathrm{j}$ or $\mathrm{s}$, then the expected geminated consonant is replaced by the cluster $-\mathrm{Cy}$. This set corresponds to typically non-geminating consonants.

(i) $\quad \mathrm{M}$ form $/ \mathrm{ka} /$ :
a. $/ \mathrm{ka} / \rightarrow[\mathrm{ha}] /$ short $\operatorname{vowel}(\mathrm{a} / \mathrm{e} / \mathrm{o})$;
b. /ka/ $\rightarrow$ [ga] / long V, short $\mathrm{V}$ (other than a/e/o), glides, /g/;
c. $/ \mathrm{ka} / \rightarrow[\mathrm{a}] /$ guttural C;
d. $/ \mathrm{ka} / \rightarrow[\mathrm{ka}] /$ elsewhere.

(ii) $\mathrm{F}$ form $/ \mathrm{ta} /$ :
a. $/ \mathrm{ta} / \rightarrow[\mathrm{da}] / \mathrm{V}$, guttural C, $/ \mathrm{d} /$;
b. $/ \mathrm{ta} / \rightarrow[\mathrm{da}] / / \mathrm{d} /$;
c. $\mid \mathrm{ta} / \rightarrow[\mathrm{ta}] /$ elsewhere.

In addition to the rules above, note that when a $\mathrm{F}$ noun ending in $/ \mathrm{l} /$ is followed by the determiner /ta/, the sequence /lt/ surfaces as [J]: bil 'month' vs. bisha 'the month'. amours 'the beautiful loves (F)'. Italian has a small group of nouns behaving as follows: uovo 'egg.M-sg.' vs. uova 'egg.F-pl.'.

Orwin (1995:33) claims that these nouns have 'mostly more than one syllable'. 
Class 3 and 4 contain only masculine nouns which do not change their gender in the plural. Nouns in class 3 are all bisyllabic in the singular, and the two vowels are identical: $\mathrm{C}(\mathrm{V}) \mathrm{V}_{i} \mathrm{CV}_{i} \mathrm{C}$. The $\mathrm{TA}$ is on the penultimate vowel. In the plural, the suffix - $o$ is added, and $V_{2}$ undergoes syncope. As a consequence, the syllabic structure of these plurals is $\mathrm{C}(\mathrm{V}) \mathrm{VCC}$. Nouns in class 4 have a predictable syllabic structure, too. This has the shape $\mathrm{C}(\mathrm{V}) \mathrm{VC}$, that is a closed syllable with either a short or a long vowel. Their gender is masculine in both singular and plural, and the TA is associated to the penultimate vowel. If the noun is monosyllabic with a short vowel, then the unique vowel bears the TA: dáb 'fire'. The interesting feature of these nouns is the way their plural is formed. First, the vowel /a/ is inserted at the end of the stem; then a copy of the last consonant of the stem is added to its right. ${ }^{11}$

Finally, class 5 is a case apart, as it is the only noun class whose nouns do not pluralize by affixating any segmental material. As a matter of fact, class 5 includes nouns of 1 to 3 syllables, that have a penultimate TA and are all masculine in the singular. ${ }^{12}$ Their plural form has a final TA and feminine gender. The only formal change between singular and plural is the TA shift one vowel rightward.

For a sake of clarity, the following list sums up the criteria to identify the inflectional classes:

(2) a. the place of TA in the singular:

(i) on the penultimate vowel (classes 2, 3, 4 and 5),

(ii) on the last vowel (class 1).

b. the shape of the plural:

(i) the suffix $-o$ (classes 1 and 3 ),

(ii) the gemination of final $C$ and suffixation of $-o$ (class 2$)$,

(iii) reduplication of final $C$ and infixation of $-a$ - (class 4 ),

(iv) no suffix (class 5).

11 According to Banti (1988), Puglielli \& Siyaad (1984) and Saeed (1999), plurals of classes 1 to 4 bear the TA on their last vowel. On the other hand, Saeed (1993) and Orwin (1995) propose that these plurals have no high tone at all. Finally, according to Le Gac (2001:109-152), plurals in -o (which belong to the accentual class 4 ) do have a high pitch when they are focussed, but no TA is present when they are in a non focussed position. This situation is clearly controversial, but it will be shown that it does not affect the hypotheses this paper defends.

12 Only closed syllables with a short vowel are forbidden in this group, as this situation corresponds to class 4 nouns.

BAALL 5 (2013) 118-159 
c. the gender of the plural with respect to the singular:

(i) $\mathrm{M}$ (sg. = F: class 1$)$,

(ii) $\mathrm{F}$ (sg. = M: classes 2 and 5 ),

(iii) $\mathrm{M}($ sg. = M: classes 3 and 4$)$.

Each criterium above is worth a few additional observations.

The place of TA in the singular is predictable from its gender: feminine nouns have a final TA (class 1), whereas masculine ones have a penultimate one (classes 2 to 5 ). The following statements are then assumed:

(3) The connection between TA and gender in the singular

a. the TA is associated to the final vowel of feminine nouns;

b. the TA is associated to the penultimate vowel of masculine nouns.

Now, the shape of the plural is interesting with respect to its gender. Indeed, reduplicated plurals are masculine, and are always derived from masculine nouns. We can thus generalize that the gender can change in the plural only if the plural is formed either (i) by the suffix -o, (ii) by the gemination of final C and the suffixation of - $o$ or (iii) by no suffix. In addition to this generalization, it is also true that if a noun is pluralized only by moving its TA rightwards, then its singular form is masculine. The TA movement is the only surface phenomenon applying to class 5 plurals. In addition, note that moving a tone can also trigger the change of gender or case, as shown in what follows:

TABLE 3 TA and inflection

\begin{tabular}{|c|c|c|c|c|c|c|}
\hline & & Form 1 & & Form 2 & & \\
\hline 1 & number & mádax & sg. & madáx & pl. & 'head' \\
\hline 2 & gender & ínan & M & inán & $\mathrm{F}$ & 'boy' vs. 'girl' \\
\hline 3 & case & géri & $\mathrm{ABS}$ & gerí & GEN & 'giraffe' \\
\hline
\end{tabular}

In the first example, TA movement entails pluralization, as already noticed, but is accompanied by gender polarity. In line 2, ínan is $\mathrm{M}$ whereas inán is $\mathrm{F}$ : in this case, we have two different lexemes, 'boy' and 'girl'. In line 3 , a noun like géri undergoes TA movement in order to change its syntactic case, but not the gender (géri is M).

The next section is dedicated to the analysis of the data discussed so far. 
In this section, I first propose that only one plural marker exists in the language; then I show that a certain group of roots are templatic, whereas other are not. This situation has a consequence in the way nouns form their plural. Then, following Godon (1998), I make the hypothesis that F gender is marked by an underlying object which is suffixed to the stem. This item is a CV unit, and is responsible for the final position of the TA in nouns like inán 'girl', F. Finally, I concentrate on syntactic cases, and I distinguish an exponent for each one of them.

\subsection{A Single Plural Marker}

In this subsection, I explore the hypothesis that only one plural marker has to be postulated. This marker is the vowel [o]. Thus, TA movement is not a strategy to pluralize a noun, but rather the consequence of another phenomenon. ${ }^{13}$ The following points are crucial in developing the hypothesis of a single plural marker:

(4) a. the directionality of TA movement;

b. the restrictiveness of reduplication;

c. the suffix -o has no inherent gender, and it alternates with $-a$ when the noun is suffixed.

Let us start with the directionality of the TA movement. TA shift is the only change that occurs in class 5 in the passage from singular to plural. The tonal variation can be used to mark the plural only if the singular noun is masculine, the reverse situation being ungrammatical:

(5) TA movement directionality

a. búug 'book' $\mathrm{M} \rightarrow$ buúg 'books' F;

b. naág 'woman' $\mathrm{F}^{*} \rightarrow$ * náag 'women' M.

Pairs like the one in (5-b) do not exist in the language. This situation is in contrast with the fact that gender polarity works for both genders: an $\mathrm{M}$ noun can be F in plural (classes 2 and 5 ) and an F noun can be $\mathrm{M}$ in plural (class 1 ). In the former case, the pluralization is accompanied by either TA movement or suf-

13 Cf. section $3 \cdot 3$.

BAALL 5 (2013) 118-159 
fixation, whereas in the latter case, only the suffixation is possible. Therefore, I make the hypothesis that the tonal variation is not involved with pluralization, or at least that it is not the primary source to pluralize a noun. In fact, the change of the tonal pattern is a consequence of the presence of an underlying F marker, as it will be demonstrated later in 3.3.

As for reduplication, its application is highly restricted. In fact, in order for a noun to be pluralized by reduplicating the last consonant of its stem, two conditions must be met: the presence of a fixed syllabic structure $(\mathrm{CV}(\mathrm{V}) \mathrm{C})$, and the masculine gender. The former condition corresponds to the obligation to have one syllable with either a short or a long vowel. In CVCV-Theory terms, the representation of a closed syllable having a short vowel is CVCV, whereas a closed syllable having a long vowel is represented as CVCVCV. Hence, the sequence $\mathrm{CV}_{1}+(\mathrm{CV})+\mathrm{CV}_{2}$ represents both situations, where parentheses point to the optionality of vowel length. Miis 'table' M sg. ABS has the following representation:

(6) Representation of muis 'table' M sg. ABS:

a. V-pos

2

$\mathrm{TA}$

Segments

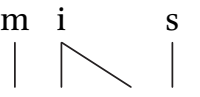

Template

C $\underline{\mathrm{V}}(\mathrm{CV}) \mathrm{C} \mathrm{V} \quad$ mís

The tier labelled TA indicates the position of the high tone with respect to the vowel. Vocalic positions are numbered from right to left. ${ }^{14}$

The plural miisás is formed by reduplicating the last consonant. As wordfinal geminates are not possible in Somali, the language must avoid such a situation. One might think that /a/ is the epenthetic vowel in Somali, as it appears between the two identical C's. However, Somali uses two different strategies to avoid final CC\# clusters: either the first vowel of the stem is copied (e.g. filin, cf. English 'film', báxar, cf. Arabic baћr 'sea'), or an epenthetic /i/ is inserted (e.g. bánki, cf. English 'bank', qálbi, cf. Arabic qalb 'heart'). We conclude that $/ \mathrm{a} /$ is not the epenthetic vowel, but rather the exponent of

14 Final V positions are excluded from this computation. Cf. Kaye (1990) for an analysis on final empty nuclei. 
another phenomenon: my hypothesis is that it is an allomorph of the plural marker.

Now, note that in CVCV-Theory terms, the template of these plurals must be $\mathrm{CV}_{1}+(\mathrm{CV})+\mathrm{CV}_{2}+\mathrm{CV}_{3}$. The complete representation of this form is shown below:

(7) Representation of miisás 'table' M pl. ABS:

a. V-pos

$\mathrm{TA}$

TA

Segments

Template

Plural<smiles>CSC1CC1[AlH2]</smiles>

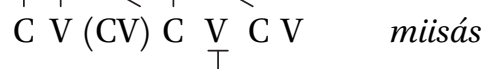

In order to unify the representations of singular and plural, I make the hypothesis that a unique underlying template exists for the nouns of class 3. This template has the shape $\mathrm{CV}_{1}+(\mathrm{CV})+\mathrm{CV}_{2}+\mathrm{CV}_{3}$ and it accounts for both singular and plural forms. The roots of this class have the form $/ \mathrm{C}_{1} \mathrm{VC}_{2} \mathrm{C}_{2} /$, and the second $\mathrm{C} 2$ surfaces only at plural, when $/ \mathrm{a} /$ is inserted. Following the pioneering work by McCarthy (1981), I consider that $\mathrm{C} 2$ propagates rightwards when a given condition is met, namely pluralization. On the other hand, $\mathrm{C} 2$ never propagates in the singular. By attributing a single template to both singular and plural forms, the template and the number feature are dissociated. Indeed, my hypothesis is that the fixed template is the expression of a lexical constraint on a particular class of roots, whereas the inserted $-a$ - is the actual plural marker. Despite its appearance, this vowel is not epenthetic.

Finally, we have classes 1,2 and 3 , which pluralize by suffixating $-o$. This object has a few interesting properties. First, it has no inherent gender, as $o$ plurals are either masculine (cf. naagó 'women' or garbó 'shoulders') or feminine (cf. albaabbó 'doors'). Secondly, it alternates with - $a$-. This happens when the plural noun is in premodifier form, as shown in what follows: 15

15 Other examples are in table 2 above. 
(8) a. naagó 'women' $\rightarrow$ naagáha 'the women'

b. garbó 'shoulders' $\rightarrow$ garbáha 'the shoulders'

c. albaabbó 'doors' $\rightarrow$ albaabbáda 'the doors'

This alternation is morphologically restricted, hence it is not phonologically conditioned. ${ }^{16}$ Crucially, final [a]'s exist, and interconsonantal [o]'s, too, as the examples below show:

(9) a. [a]\#: naagáha 'the women', galábta 'the afternoon', etc.

b. Co(o)C: qódob 'article', górgor 'vulture', xóog 'force', qólay 'bag', etc.

Then, plural formation (or, more generally, a morphological operation) may be the only cause of such an alternation. In other words, [a] and [o] are two distinct realizations of the same morpheme, i.e. the plural morpheme.

Interestingly, the vowels /o/ and /a/ share some phonological substance. The theory of Elements (Kaye et al., 1985; Kaye et al., 1990) argues for the existence of phonological basic matrix Elements generating complex vowels. In this sense, the decomposition of /o/ and /a/ gives an interesting result, as can be seen below (capital letters indicate the basic Element):

(10) Phonological decomposition of vowels

a. $[\mathrm{o}]=\mid \mathrm{A} . \mathrm{U} /$

b. $[\mathrm{a}]=\mid \mathrm{A} /$

The Element /A/ is shared by both vowels.

From the representations above, we can hypothesize that the plural suffix /o/ has the following underlying structure:

16 As far as I know, there is only one other striking example of such an alternation in Somali morphology. This happens in conjugation 3 verbs, also known as the 'autobenefactive' form (cf. Saeed 1993:51-58, and Orwin 1995:82-84), i.e. qaadó 'to take for oneself'; joogsó 'to stop', etc. These verbs are characterized by final - $o$ in imperative singular, which is the only bare form in the paradigm. Finite verbal forms are created by adding suffixes to the stem of the imperative singular. Crucially, final -o is always replaced by $-a$-, as a few examples from past tense illustrate: 1sg. joogsa-day 'I stopped', 2sg. joogsa-tay 'you stopped', 1pl. joogsa-nnay 'we stopped', 2pl. joogsa-teen 'you stopped', etc. 
(11) Structure of the suffix -o:

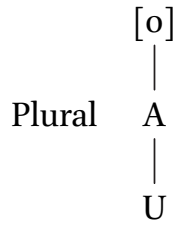

The representation in (11) underlies the surface suffix $-o$. In addition, I propose that the same complex vowel underlies internal plural $-a$-, which appears in the context of reduplicated plurals, cf. class 4 above in (7). The alternation between [o] and [a] can be formalized by the de-linking of the association line between the Element $/ \mathrm{U} /$ and the Element $/ \mathrm{A} /$, as the examples below show:

(12) Plural suffix alternation:
a. Segments
a
Template
C V C V C V
[naagó] 'women'
Plural
A
U

b. Segments<smiles>C[AlH]C(C)C(C)C</smiles>

Template

Plural

A

$\mathrm{U}$

In DM terms, each exponent corresponds to a Vocabulary Item (henceforth VI). A VI is a relation between a given phonological exponent and the morphosyntactic information about where that exponent must be inserted in the structure. In the case at hand, we need two VI's: one for the sg. and one for the pl. (sg. exponent is clearly zero):

BAALL 5 (2013) 118-159 
(13) VI's for number in Somali nouns

a. $[-\mathrm{pl}] \leftrightarrow \varnothing$

b. $[+\mathrm{pl}] \leftrightarrow \mathrm{A}$

The list above accounts for the number exponents of classes 1, 2, 3 and 4, and has the advantage of postulating only one phonological string for each given morpheme. ${ }^{17}$ In section 4 , we will see that the same hypothesis also explains the plurals of class 5 , in which there is TA movement and no apparent segmental suffix (cf. mádax vs. madáx 'head(s)').

The following subsection is dedicated to the comparison between class 3 and class 4 with respect to their templates.

\subsection{Templatic Nouns}

Somali roots can have a fixed length. In fact, both classes 3 and 4 contain nouns that have a predictable form of their roots. Through the comparison between the representations (6) and (7), the hypothesis was made that nouns of class 4 share a unique template of the form $\mathrm{CV}_{1}+(\mathrm{CV})+\mathrm{CV}_{2}+\mathrm{CV}_{3}$. This sequence of CV units recalls Guerssel and Lowenstamm's (1996) unique template for classical Arabic verbal forms. In their idea, the optional CV is activated only once through a given derivational morphological operation. This way, only one of the two optional positions is occupied. In Somali nouns, this position is always the vocalic one, and it is activated when a particular kind of noun is formed. Hence, its activation is strictly lexical.

The fixed template $\mathrm{CV}_{1}+(\mathrm{CV})+\mathrm{CV}_{2}+\mathrm{CV}_{3}$ appears to fit the nouns in class 3 , too. Indeed, all nouns in this group are bisyllabic, the first vowel is either short or long, and the second vowel, which is identical to the first one, is always short. In other words, the size of a noun in class 4 is maximally four CV units and minimally three. Both class are exclusively masculine, and they do not display gender polarity.

The representations of gárab 'shoulder', dáb 'fire' and míis 'table' are shown below:

17 In addition to the list (13), the presence of the uniform template for class 4 must be known, too. This becomes explicit in the following section. 
(14) gárab 'shoulder' M sg. ABS, dáb 'fire’ M sg. ABS and míis 'table' M sg. ABS:

a. V-pos

TA

Segments

Template

b. V-pos

$\mathrm{TA}$

Segments

Template

c. V-pos

$\mathrm{TA}$

Segments

Template
$\mathrm{TA}$

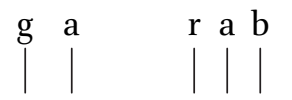

C $\underline{V}(\mathrm{CV}) \mathrm{C}$ V C V

[gárab] class 3
$\mathrm{TA}$

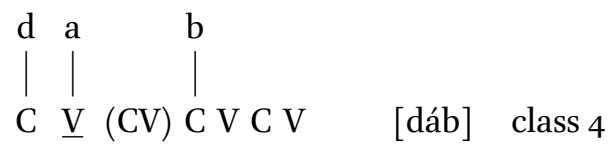

Recall that the syllable between parentheses is activated only if $V_{1}$ is long, as in the case of miis, otherwise it is erased. ${ }^{18}$ In Somali, the length of the vowel is a lexical property of the root. Note that the TA association proceeds from the right to the left. In addition, it is strictly vowel-sensitive, as it affects the second activated vocalic position in the template, unless only one short vowel is present (cf. dáb). We can then conclude that only one group exists, henceforth labelled class $3 / 4$. This class has the following three properties:

(15) Class 3/4:

a. roots have a uniform and fixed template: $\mathrm{CV}_{1}+(\mathrm{CV})+\mathrm{CV}_{2}+\mathrm{CV}_{3}$;

b. the nouns are all masculine;

c. no gender polarity is observed.

18 This is an intrinsic property of CV units: if they are not used, they are erased.

BAALL 5 (2013) 118-159 
On the other hand, nouns from classes 1,2 and 5 do not require any templatic restriction, as it can be seen from data in table 2.

My hypothesis is that a root dichotomy exists in Somali nouns. A set of roots are represented as lexically associated to their CVCV tiers. These are the roots entailing classes 1,2 and 5 , that is the ones whose the form and the length of the skeletal tier is not fixed. In terms of spell-out, such a root is realized as a segmental sequence associated to a skeletal tier: ${ }^{19}$

(16) VI's for lexical template roots

a. 'woman' $\leftrightarrow$

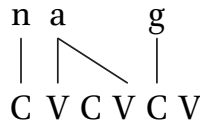

class 1

b. 'door' $\leftrightarrow$

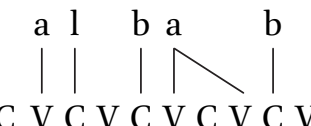
class 2

c. 'head' $\leftrightarrow$

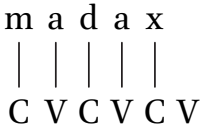
class 5

On the other side, the set of roots selecting for a uniform and fixed template (that is the ones in class $3 / 4$ ), do not contain this template in their lexical representation. This way, the skeletal tier $\mathrm{CV}_{1}+(\mathrm{CV})+\mathrm{CV}_{2}+\mathrm{CV}_{3}$ must be spelled-out elsewhere in the structure, as will be shown later in section 4 . These roots have a strictly segmental spell-out, in the terms of Bendjaballah and Haiden's (2008) taxonomy:

(17) VI's for predictable template roots

a. 'table' $\leftrightarrow$ MIIS class $3 / 4$

b. 'fire' $\leftrightarrow$ DAG class $3 / 4$

The question arises as to why roots in (17) need to have a template. In Autosegmental Phonology terms, a segment needs to be associated to a skeletal position in order to be audible at the surface level. Thus, if a root without a templatic tier enters a derivation, such a tier must be provided at some level. Its VI is formalized as follows:

19 Cf. Bendjaballah \& Haiden (2008) for a typology of spell-out. 
(18) Template $\leftrightarrow \mathrm{CV}_{1}+(\mathrm{CV})+\mathrm{CV}_{2}+\mathrm{CV}_{3}$

In conclusion, the fundamental difference between the two kinds of roots is the following: in one case roots enter the structure with no skeletal positions, whereas in the other they are inserted with a skeletal tier.

\subsection{The Feminine Exponent and the Gender Polarity}

Godon (1998:71-82) argues that feminine gender in Somali nouns depends on the presence of an underlying CV in their representations. More specifically, a $\mathrm{CV}$ syllable attached to the right edge of a masculine noun is responsible for the tonal accent shift and thus for a feminine interpretation. This syllable is external. ${ }^{20}$ The tonal difference between masculine and feminine nouns is a consequence of the presence of a phonological abstract syllable, illustrated by the following examples:

(19) ínan 'boy', M vs. inán 'girl', F:21

a. V-pos

$\mathrm{TA}$

\section{TA}

Segments

Template

i $\quad \mathrm{n} \quad \mathrm{a} \quad \mathrm{m}$

$1 \mid 1$

[ínan] M sg.

b. V-pos

$\mathrm{TA}$

TA

Segments

i $\mathrm{n}$ a $\mathrm{m}$

Template

C V C $\mathrm{V} C \mathrm{~V}+\mathrm{CV}$

[inán] F sg.

20 In my analysis, it is the spell-out of the feature [+F], which is introduced by $\mathrm{n}^{0}($ an external site, with respect to the root). This view avoids the following ambiguity: as nouns like dáb or míis do have an extra CV in their representations (cf. (14)), one could claim that they should be F, too. This is not possible if the F interpretation is made via a feature $[+F]$. The spell-out of this feature is an external $\mathrm{CV}$, which is only phonologically equivalent to the one in dáb. Morpho-syntactically, they are different objects.

21 In Somali, /m/ neutralizes in favor of [n] when it occurs in final codas (cf. Saeed, 1999:301). Thus, the underlying form is /inam/ for both [ínan] and [inán].

BAALL 5 (2013) 118-159 
The arguments for such a hypothesis are the following:

(20) Arguments for the F marker:

a. the gemination of the last consonant in F plurals (class 2);

b. the alternation of the TA between singular and plural in class 5;

c. the generalization on the position of the TA.

Let us begin with the first argument. Interestingly, class 2 plurals are formed not only by the suffix /A.U/ (cf. above (13-b)), but also by the gemination of the last consonant of the stem, as shown below:

(21) Gemination at plural (class 2)

albáab M sg. $\rightarrow$ albaabbó F pl. 'door(s)'

Nouns in class 5 , in turn, do not display the expected plural suffix (13-b). Instead, they only show the TA movement one vowel rightwards, as already mentioned:

(22) TA movement at plural (class 5 )

mádax M sg. $\rightarrow$ madáx $\mathrm{F}$ pl. 'head(s)'

It is important to note that a plural noun is feminine either when there is suffixation of - $o$ followed by this gemination, or when the TA moves one vowel rightwards. Inversely, a plural noun is masculine when - $o$ is added (cf. class 1: naagó, class 3/4: miisás). The hypothesis I make is that an external CV unit corresponds to the F gender. This way, the gemination in (21) can be explained by the same token as TA movement in (22). In addition, the position of the TA is always the second $\mathrm{V}$ slot from the right. This situation is illustrated below, by using class 2 and 5 , respectively:

(23) Additional CV syllable at plural (classes 2 and 5): albáab 'door' and mádax 'head'

a. V-pos

21

TA

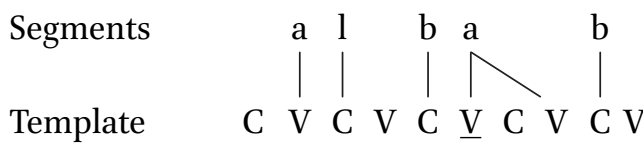

TA

[albáab] M sg. 
b. V-pos

TA

Segments

Template

Plural

c. V-pos

TA

Segments

Template

d. V-pos

TA

Segments

Template

Plural
TA

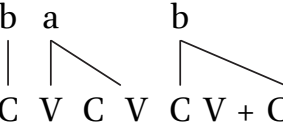

C $\mathrm{V} C \mathrm{C}$

C V C $\underline{\mathrm{V}} \mathrm{C} \mathrm{V}+\mathrm{C}$ V [albaabbó] F pl.

$\left.\right|_{U}$

$2 \quad 1$

TA

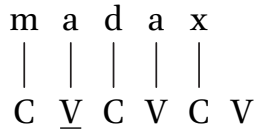

[mádax] M sg.

$\left.\right|_{\mathrm{U}} ^{\mathrm{A}}$

Note that the exception to the generalization on the position of the TA is represented by plurals displaying the suffix $-o$. Indeed, these plurals display a TA on the plural suffix [ó], or they do not carry it, as we have already mentioned (cf. Puglielli \& Siyaad, 1984; Saeed, 1999). But in class 5, where the suffix -o does not appear, the TA surfaces on the predicted position: the second vowel from the right. The introduction of an abstract $\mathrm{CV}$ provides a regular pattern for the TA with respect to its position: it is always found on the penultimate vocalic position. The consequence of such an analysis is the following:

BAALL 5 (2013) 118-159 
(24) The TA is independent from the gender.

Thus, feminine is marked by a suffixed CV syllable, whereas masculine gender is marked by zero.

The hypothesis on F gender straightforwardly explains the gemination observed in class 2 , as can be seen easily in the representations above in (23-b). In addition, the introduction of this abstract syllable explains the alternation of the TA in class 5 , because it follows the general principle that the TA is always associated to the second $V$ position from right to left. ${ }^{22}$ This last statement constitutes the third argument in favor of the additional CV-hypothesis: we can untie the link between the position of the TA and the gender.

In addition, my hypothesis on feminine exponent does not contradict similar facts from other Afroasiatic languages. First, in her Rendille analysis, Oomen (1981:44-48) proposes a feminine suffix for Proto-Cushitic languages having the form * $a t .^{23}$ Accepting this hypothesis entails that all nouns bore a tone on the penultimate vowel, exactly like in Somali. After the loss of this suffix, only the accentuation makes the genders distinct at surface level. As for plural, Oomen (1981:51-53) proposes a stressed suffix *át. At the loss of the consonant, *-a would become $-o$, the actual plural suffix. This would explain the alternation a/o which is visible in Somali plurals. The fact that the plural suffix can eventually attract the stress/tone can also be attributed to an underlying stressed plural suffix *-át. Second, the general Semitic feminine suffix is also *at. Languages like Arabic lost in some cases the consonant, whereas - $a$ still holds, i.e. madrasa 'school'. There is actually an example of *-at in Somali, namely the suffix -eed for genitive feminine nouns. ${ }^{24}$ This suffix can be regarded as a reflex of an old feminine suffix. Third, Nubi, an Arabic-based creole language, has a few interesting cases of alternations singular/plural where the distinct phonological feature is the position of the stress (cf. Kihm, 2010): gidida ( $\mathrm{sg}$ ) vs. gididá (pl) 'chicken(s)', béle (sg) vs. belé (pl) 'countr-y/ies' and siádum (sg) vs. siadúm (pl) 'owner(s)'. Somali behaves like Nubi with respect to the prosodic alternation between the singular and the plural.

We can now go back to the hypothesis on feminine gender. Again, this situation can be formalized in DM terms as it is shown below:

\footnotetext{
22 The absence of the suffix [o] is explained later, in section 4.

23 She actually proposes a ${ }^{*}$-et suffix for Rendille and ${ }^{*}$-at as a historical common feminine marker. Note that Rendille nouns display polarity in a very similar way to Somali ones.

24 It will be treated later in more details.
} 
(25) Gender exponents

a. $\mathrm{M} \leftrightarrow$ zero

b. F $\leftrightarrow$ suffixed CV

If gender polarity is an epiphenomenon, resulting from the presence of a suffixed syllable which is the exponent of the feminine gender, the question is raised as to the role of the TA, and its relationship with syntactic case.

\subsection{Case Exponents}

In this subsection, I aim at establishing a VI for each syntactic case. As mentioned above in section 2, Somali has three main syntactic cases, namely ABS(solutive), NOM(inative) and GEN(itive). Recall that the ABS is syntactically the default case, as well as the unmarked one. ${ }^{25}$ As for the NOM and the GEN, I propose that the former corresponds to the matrix [-oblique], whereas the latter to the matrix [+oblique] (cf. Halle 1997). The matrices for each case are shown below:

(26) Somali case matrices:
a. NOM: [-oblique]
b. GEN: [+oblique]
c. ABS: [default]

Now, the question is raised as to the nature of the phonological exponents corresponding to the spell-out of each case. One phonological object has not received a role, yet. This is the TA, as it is involved neither in pluralization nor in feminine gender formation. I propose that the TA marks the syntactic case in Somali nouns.

We observed in (3) above that the TA has two different positions in the ABS case, depending on the gender of the noun. We explained this fact by arguing that a CV suffix marks the feminine gender (cf. supra section 3.3). As a consequence, the TA is always associated to the second vowel from the right, regardless the gender of the noun. ${ }^{26}$ If gender is marked by an extra CV unit, it follows that the ABS case is marked by the TA associated to a given vowel, namely the second from the right. The VI associated to this case is shown below:

(27) ABS: [default $] \leftrightarrow$ TA on the 2 nd V position

\footnotetext{
25 Cf. Frascarelli \& Puglielli (2005), Orwin (1995), Saeed (1993).

26 Plurals which have a final tone (or are tone-less), are explained later in section 4.
} 
Now, note that the presence of two or more TA's on a noun is prohibited. Thus, two logical possibilities exist for the other cases. One must be marked by the absence of the TA whereas the other must be marked by the TA associated to the last vowel. The latter situation corresponds to the NOM and the former to the GEN.

NOM is indeed characterized by the absence of high tone, as Saeed (1993:142) observes: "subject case lowers high tones". In addition, feminine nouns add the suffix $-i$ :

TABLE 4 NOM markings

\begin{tabular}{|c|c|c|c|c|c|c|}
\hline & Absolutive & Nominative & Class & Gender & Number & \\
\hline \multirow{2}{*}{\multicolumn{2}{|c|}{ 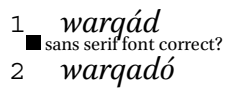 }} & warqad $-i$ & 1 & $\mathrm{~F}$ & sg. & 'letter' \\
\hline & & warqado & 1 & M & pl. & 'letters' \\
\hline 3 & albáab & albaab & 2 & M & sg. & 'door’ \\
\hline 4 & albaabbó & albaabbo & 2 & $\mathrm{~F}$ & pl. & 'doors' \\
\hline 5 & míis & miis & $3 / 4$ & $\mathrm{M}$ & sg. & 'table' \\
\hline 6 & miisás & miisas & $3 / 4$ & M & pl. & 'tables' \\
\hline 7 & mádax & $\operatorname{madax}$ & 5 & M & sg. & 'head' \\
\hline 8 & madáx & $\operatorname{madax}-i$ & 5 & $\mathrm{~F}$ & pl. & 'heads' \\
\hline
\end{tabular}

Two facts need further explanation. First, feminine NOM marking $-i$ is attached to the last or rightmost element of the phrase, unless this is the determiner. ${ }^{27}$ Secondly, the elements that precede the noun bearing NOM marking take the ABS case, i.e. they do carry a TA. This situation is part of the phenomenon which imposes ABS marking on nouns in pre-determiner position, the position we have been referring to as the 'premodifier form' since the beginning of the paper.

As a conclusion, I propose that the phonological exponent of the NOM case is the suffix - $i$; no TA is spelled-out:

(28) NOM: [-oblique] $\leftrightarrow-\mathrm{i}$

The VI (28) applies to the feature [-oblique]. In other words, the insertion of the exponent $-i$ does not depend on the gender associated to the root. As a

27 The situation is quite complex, and it will not be treated in the present study. 
consequence, the prediction is made that all NOM nouns should display such an exponent.

Recall the hypothesis on feminine gender, formulated above in $\left(25^{-b}\right)$ : a suffixed CV spells out the feature [+F]. If $\mathrm{F}$ nouns are suffixed, then they have additional templatic positions. NOM marking $-i$ lands on the $\mathrm{V}$ position belonging to the $\mathrm{F}$ exponent. By hypothesis, the final $\mathrm{V}$ position of the template of the root is not accessible to inflection. Thus, the marker $-i$ does not appear in masculine nouns. This is compatible with the cyclic derivation of DM.

The $-i$ suffix has two interesting phonological properties: (i) it does not have a palatalizing effect, and (ii) it triggers the rule $/ \mathrm{m} / \rightarrow[\mathrm{n}] / \#$. Both phenomena confirm that the hypothesis on the phonological exponent of the NOM is on the right track. Observe the data below:

TABLE 5 Phonological properties of NOM suffix ${ }^{28}$

\begin{tabular}{|c|c|c|c|c|c|c|}
\hline & $\begin{array}{l}\text { Singular } \\
\text { bare noun }\end{array}$ & Premodifier & & $\begin{array}{l}\text { Plural } \\
\text { bare noun }\end{array}$ & Premodifier & \\
\hline class $1 \mathrm{~F}$ & naagi & naág-tu & M & naago & naagú-hu & 'woman/women' \\
\hline class $1 \mathrm{~F}$ & inani & inán-tu & M & inamo & inamú-hu & 'girl(s)' \\
\hline class $2 \mathrm{M}$ & inan & ínan-ku & $\mathrm{F}$ & inammo & inammá-du & 'boy(s)' \\
\hline
\end{tabular}

The causative suffix $-i$ normally triggers palatalization in Somali, as in the case of causative verbs: joog 'to stop' vs. jooji 'to arrest', nuug 'to suck' vs. nuuji 'to suckle' or daaq 'to graze' vs. daaji 'to make graze. ${ }^{29}$

Despite its identical phonological shape, NOM $-i$ does not behave like the causative marker. This is shown in the first line of the table 5 . I argue that NOM $-i$ does not palatalize because intervening free positions on the template occur between the last activated consonant in the stem and the position the suffix $-i$ is associated to. In other words, the suffix $-i$ is not adjacent to the last consonant of the root, i.e. $-g$.

In addition, underlying $/ \mathrm{m} /$ surfaces as [n] when in final positions, as in inan. Again, why does this phenomenon occur in the context of the NOM

28 The alternation between final -o in naago and in inamo and the first - $u$ - in naagúhu and inamúhu is an instance of what is referred to as the 'transparence of gutturals' phenomenon, a situation where vowels harmonize throughout a guttural, which remains 'transparent'.

29 Cf. Bendjaballah (1998) for more details.

BAALL 5 (2013) 118-159 
marking suffixation? The answer is equivalent to the one provided for the previous situation. The underlying representation of [inani] is /inam\#i/, where final $/ \mathrm{m} /$ surfaces as $[\mathrm{n}]$. This means that the underlying $/ \mathrm{m} /$ is in a coda position.

Hence, both phenomena apply to a template-external position, which is cyclically separated from the root. ${ }^{30}$ As only feminine nouns have an external free $\mathrm{V}$ position, this allows the suffix $-i$ to surface, whereas in M nouns NOM $i$ floats and stands unassociated. Templatic representations of NOM nouns are shown below:

(29) Templatic representation of NOM nouns:
a. NOM
Segments

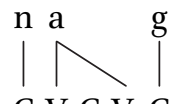
Template
$\mathrm{CVCV} \mathrm{C} \underline{\mathrm{V}}+\mathrm{C} \mathrm{V}$
[naagi] 'woman', F

b. NOM

Segments

i n a m

Template

C V C V C $\underline{V}+C$ V

[inani] 'girl', F

c. NOM

i

$\begin{array}{ll}\text { Segments } & \mathrm{i} \mathrm{n} \text { a m } \\ \text { Template } & \mathrm{C} \mathrm{V} \mathrm{C} \mathrm{V} \mathrm{C} \underline{\mathrm{V}}\end{array}$

[inan] 'boy', M

Ultimately, the reason as to why underlined $V$ positions are not accessible to the inflection is an open problem, which can be solved through a domain-related phonological approach (Kaye, 1995), a phase-based approach (Marantz, 2008) or one that treats suffixes as roots (Lowenstamm, To appear). The issue will not be further investigated in this paper, but cf. Scheer (2010) for a recent analysis of similar phenomena.

Finally we have GEN case, which is characterized by the presence of a high tone. The position of TA at GEN, however, is totally predictable: it is one vowel

Cf. Embick (2010: ch. 1) for a review of cyclic derivation mechanism. 
to the right of its position in the ABS case, that is the final one. ${ }^{31}$ In addition, $\mathrm{F}$ nouns display a segmental suffix of the the forms -eed and -ood, in singular and plural forms respectively. The table below illustrates a few examples:

TABLE 6 GEN markings

\begin{tabular}{|c|c|c|c|c|c|c|}
\hline & Absolutive & Genitive & Class & Gender & Number & \\
\hline 1 & warqád & warqad-eéd & 1 & $\mathrm{~F}$ & sg. & 'letter' \\
\hline 2 & warqadó & warqad-(oód) & 1 & M & pl. & 'letters' \\
\hline 3 & albáab & albaáb & 2 & $\mathrm{M}$ & sg. & 'door' \\
\hline 4 & albaabbó & albaabb-(oód) & 2 & $\mathrm{~F}$ & pl. & 'doors' \\
\hline 5 & míis & mils & $3 / 4$ & $\mathrm{M}$ & sg. & 'table' \\
\hline 6 & miisás & miisás & $3 / 4$ & $\mathrm{M}$ & pl. & 'tables' \\
\hline 7 & mádax & madáx & 5 & M & sg. & 'head' \\
\hline 8 & madáx & madax-oód & 5 & $\mathrm{~F}$ & pl. & 'heads' \\
\hline
\end{tabular}

In light of the hypothesis put forth for ABS and NOM cases, GEN is relatively easy to formalize. First, the TA must be associated to the last vowel. Secondly, the suffix -eed is contextually inserted. ${ }^{32}$ As for the VI, I propose the following form:

(30) GEN: [+oblique $] \leftrightarrow$ TA on the last vowel + -eed

It is important to notice that the high tone and the segmental suffix are two phonological realities of one and unique object: the GEN exponent. ${ }^{33}$

The analysis presented here emphasizes the fact that the position of the TA depends, exclusively, on the syntactic case. In other words, the position of the TA has nothing to do with either gender or number.

The next section illustrates the mechanism of noun formation at work.

31 TA is either penultimate or final at ABS, as largely commented.

32 The alternation between -eed and -ood will not be explained. However, note that in terms of the Theory of Elements, the vowels [e] and [o] share the Element /A/: this may be the correct analytical path.

33 The question is left open as to why -eed does not surface at M, as it is longer than one CV unit (the F marker). It seems, though, that additional templatic material is needed to let this object surface.

BAALL 5 (2013) 118-159 
$4 \quad$ Syntactic Structures in Somali Nouns

\subsection{Complex Heads}

I assume that noun formation proceeds along the lines drawn by DM, following a three-step derivation (cf. Embick \& Noyer, 2007):

(31) Noun formation

a. syntactic basic structure;

b. complex head formation;

c. vocabulary insertion and linearization.

This section illustrates how this mechanism works.

First, the following basic structure is found at the output of Syntax:

(32) Basic structure of a noun

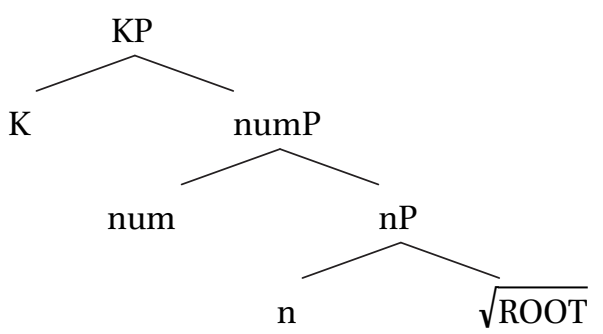

A complex head is created via cyclic head movement (cf. Embick, 2010:36-40). This operation gives rise to the syntactic structure in (33), where each terminal node hosts the feature matrix corresponding to a given morpheme. Gender is introduced by the n-head (cf. Lowenstamm, 2008), whereas num- and K-heads introduce number and case, respectively. ${ }^{34}$ The label "Th" stands for "theme", that is a node adjoined to each functional head, as in Oltra-Massuet (2000). This node is the result of a well-formedness constraint, which imposes overt morphology on nouns as far as gender, number and case are involved.

34 In Lecarme (2002:129), the Somali noun structure contains a DP instead of a KP. In my hypothesis, I follow Bittner and Hale's work (1996) where a projection KP has been introduced in order to account for languages displaying overt case morphology. DM analyses such those in Calabrese (1998), Halle (1992) and Halle \& Vaux (1998) also postulate the presence of a KP projection. 
(33) Somali noun complex head

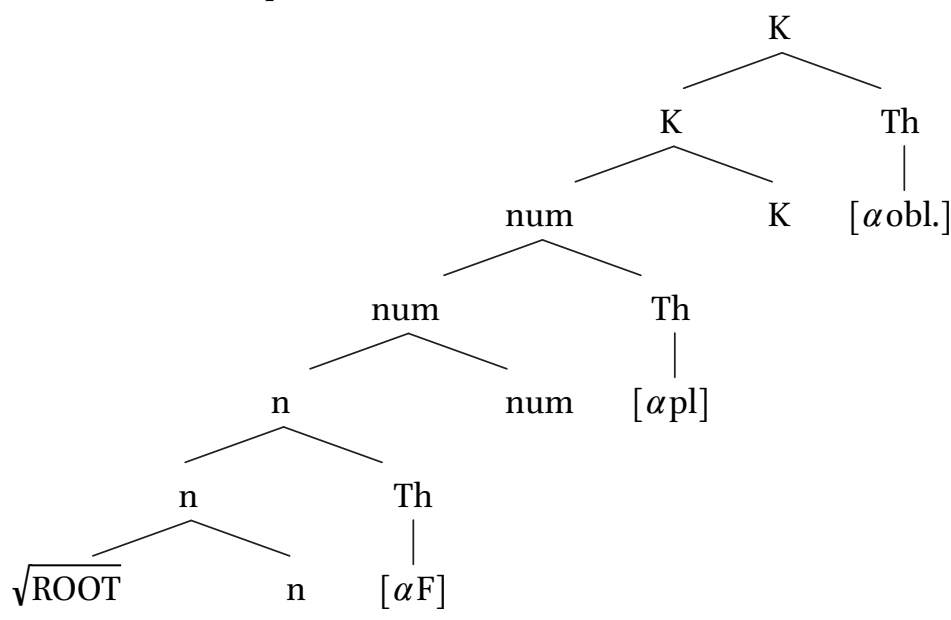

Finally, by the process of VI insertion, phonological exponents are associated to each terminal and then arranged into phonological strings. Only one phonological exponent is associated to each possible combination of features in a given matrix/morpheme. Morphological forms must be decomposed into basic morpho-phonological primes. The required VI's for Somali nouns are recapitulated below:

(34) Somali noun VI's:
a. $[-\mathrm{F}] \leftrightarrow$ zero
b. $[+\mathrm{F}] \leftrightarrow \mathrm{CV}$
c. $[-\mathrm{pl}] \leftrightarrow$ zero
d. $[+\mathrm{pl}] \leftrightarrow /$ A.U/
e. $[-$ oblique $] \leftrightarrow-i$
f. $\quad[+$ oblique $] \leftrightarrow$ last vowel TA + -eed
g. $[$ default $] \leftrightarrow$ penultimate vowel TA.

A class 2 noun, albáab 'door' is shown in the structure below, as an example. The singular structure is shown first: 
(35) Complex head and linearization for albáab 'door', M sg. ABS

a.

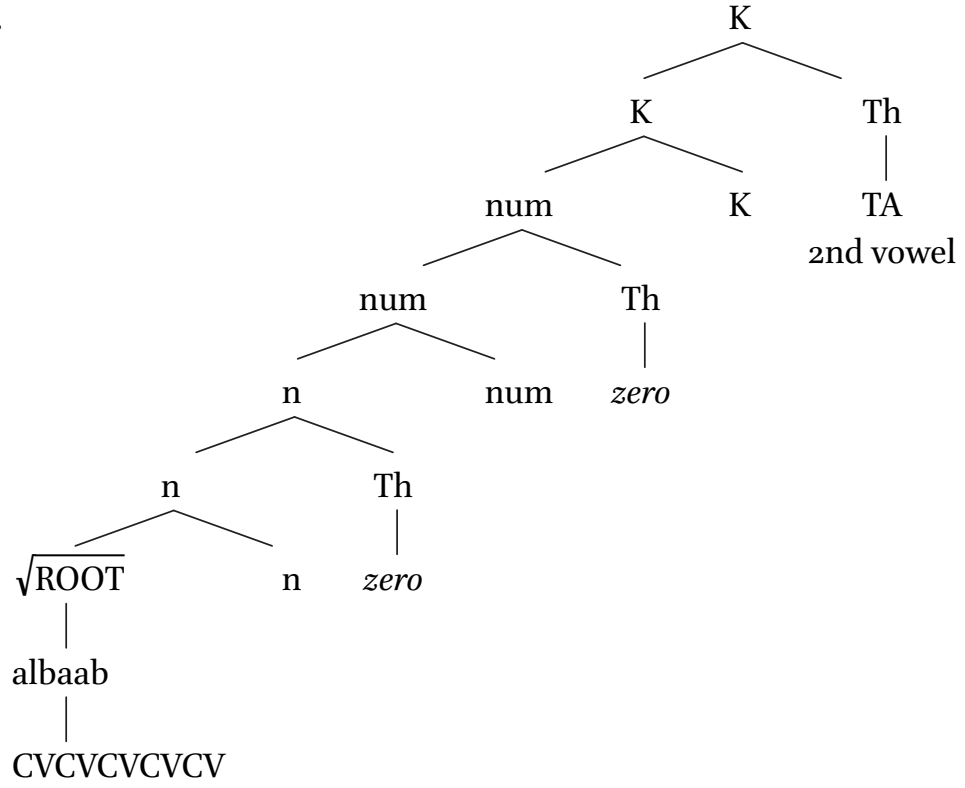

b. V-pos

$\mathrm{TA}$

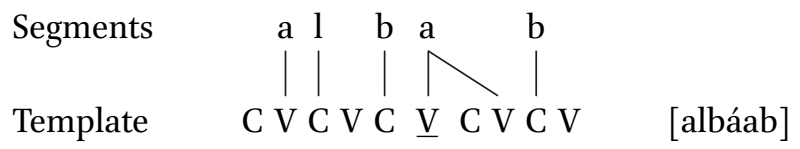

The situation depicted above in (35) is entirely derived by hypotheses on gender, number and case exponents. Phonological computation "puts together" the basic objects and derives the attested surface form. In the case at hand, a lexical template is associated to the root $\sqrt{\mathrm{ALBAAB}}$. This template is linearized in the way shown in $\left(35^{-b}\right)$. At this point, the TA is associated to the second vowel from the right.

As for the plural, the situation is identical, except for the number exponent: /A.U/ replaces the zero marker. In addition, as class 2 plurals are feminine, the exponent of the F gender must be spelled-out, too. By hypothesis, this corresponds to a suffixed CV unit, which triggers the gemination of the final consonant of the root. This situation is shown below: 
(36) Complex head and linearization for albaabbó 'doors', F pl. ABS

a.

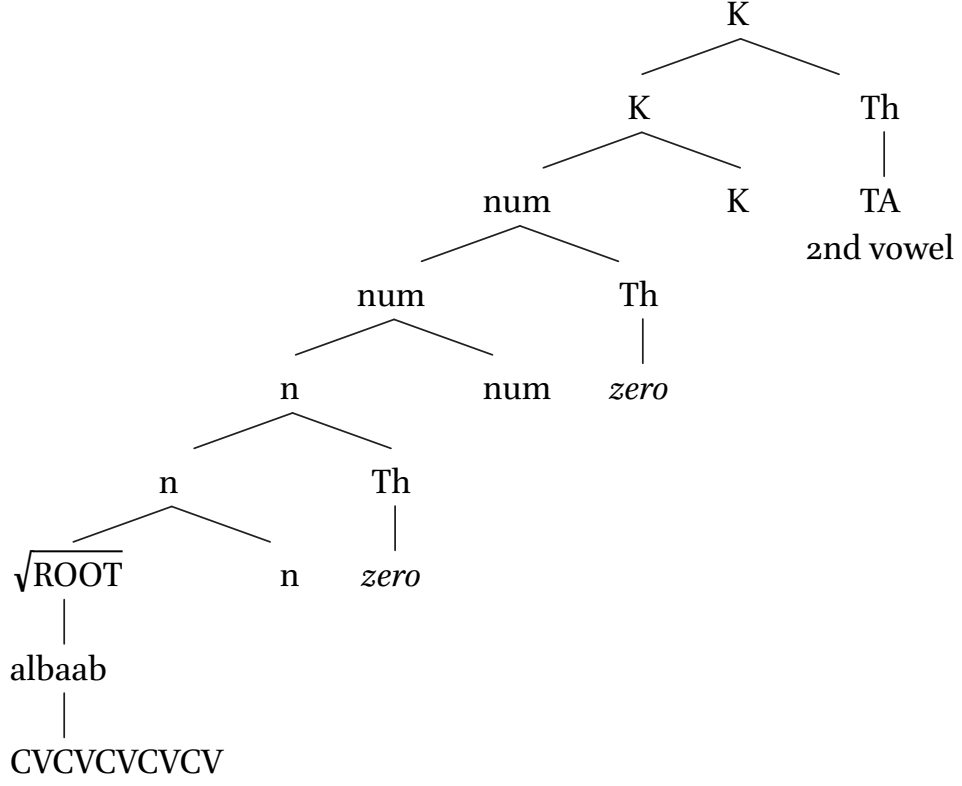

b. V-pos

$2 \quad 1$

TA

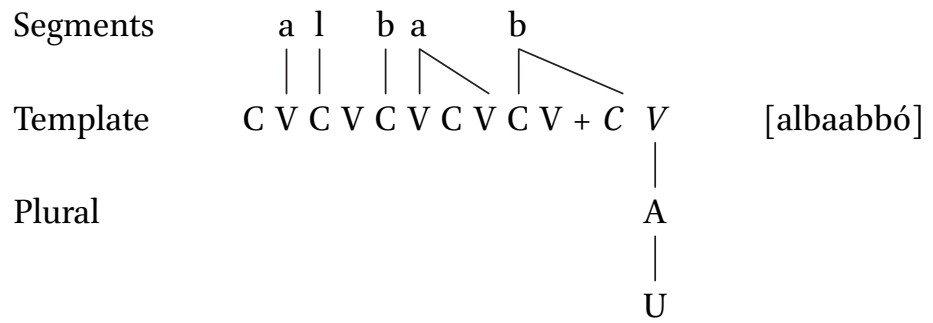

The representation of the plural raises a crucial problem, namely how is the additional syllable generated? Recall that this CV results from the spell-out of the gender $[+F]$. The root $\sqrt{\mathrm{ALBAAB}}$, which is $\mathrm{M}$ in the singular, should not trigger an $\mathrm{F}$ agreement.

I propose that the $\mathrm{CV}$ unit which marks the $\mathrm{F}$ gender is inserted after the creation of the complex head, namely at the moment of the linearization. For this reason, this syllable does not appear in (36-a), but only in (36-b) (italicized). The next section is dedicated to this and further issues raised by the analysis proposed so far.

BAALL 5 (2013) 118-159 


\subsection{Structures and Allomorphy}

The phonological decomposition proposed so far has an important consequence for the representation of the morphemes: each abstract morpheme has a unique phonological exponent. Put differently, a given morphological property always corresponds to the same phonological string, throughout the system. For instance, Somali nominal plural is always marked by the string /A.U/, and feminine gender is always expressed by the externally added CV.This hypothesis imposes strong constraints on morpho-phonological exceptions. This is the case, for example, in class 5 : these plurals do not show a segmental suffix, but only a TA shift: mádax $\mathrm{M}$ 'head' vs. madáx $\mathrm{F}$ 'heads'. At first sight, we face a counter-example to the generalization on plural morpheme, as our hypotheses predict the ungrammatical: *madaxyo (cf. class 2 daríiq M 'road' vs. dariiqyo $\mathrm{F}$ 'roads'). ${ }^{35}$

The four main problems we encountered so far are the following:

(37) Problems still to be accounted for:

a. the presence of feminine $\mathrm{CV}$ in the plural of classes 2 and 5 ;

b. class 5 plurals do not show the suffix /A.U/;

c. the way the fixed template $\mathrm{CV}_{1}+(\mathrm{CV})+\mathrm{CV}_{2}+\mathrm{CV}_{3}$ is inserted in the structure;

d. how are class 1 plurals derived?

In order to account for these exceptionalities, I propose to interpret surface exceptions as the result of the application of a few allomorphy rules, in the sense of Embick (2010:19-46). These rules apply to phonological material before the linearization, namely on terminal nodes of complex heads. They are sensitive to the position that each phonological object has in the syntactic structure. In particular, according to Embick (2010), a given object can trigger the allomorphy of another one if and only if no intervening object occurs, and they are both spelled-out in the same phase.

In this sense, the feminine $\mathrm{CV}$ in the plural of both class 2 and 5 results from the following allomorphy rule (henceforth $\mathrm{AR}$ ):

(38) Feminine allomorphy, ARı: zero $\rightarrow \mathrm{CV} / \mathrm{J} \_$A. $\mathrm{U}_{[+p l]}$

35 In standard spelling, $x$ corresponds to phonetic $[\hbar]$, one of the segments that cannot geminate. 
Technically, (38) triggers the insertion of a CV syllable in the plural, and the representation (36-b) is thus accounted for. ${ }^{36}$

Rule (38) above applies both in class 2 and 5 . In class 2, the plural suffix /A.U/ surfaces as [ó]. ${ }^{37}$ In addition, the gemination of the last consonant of the root is contextually triggered (because of the presence of an extra $\mathrm{CV}$ unit, cf. representation (23) above). On the other hand, class 5 displays a plural which does not have any apparent segmental realization. As already noticed, this plural corresponds to the TA shift from left to right. The absence of a segmental plural in this class can also be regarded as an allomorph of the plural morpheme. This object is produced by the application of the following allomorphy rule:

(39) Plural allomorphy, AR2: $/$ A.U $/_{[+p l]} \rightarrow$ zero / $\sqrt{ }$ _ (class 5 roots)

The rule above can also be seen in terms of delinking or non-association of the suffix /A.U/ from the template.

The combination of the rules (38) and (39) gives rise to class 5 nouns. The structure of plural madáx 'heads' is shown below (the singular is the same as class 2 one, cf. (35)): ${ }^{38}$

36 The hypothesis is that the root can trigger contextual allomorphy on objects which are in a local relationship with it. Locality is defined following Embick's theory (2010:32-35).

37 As already pointed out, the plural suffix /A.U/ surfaces as [ó] according to Banti (1988), Puglielli \& Siyaad (1984) and Saeed (1999), whereas for Orwin (1995) and Saeed (1993) it does not carry a TA. This problem does not affect the scope of our proposal for the following reason. Recall that the TA surfaces on the second $\mathrm{V}$ position from the right. If the suffix $-o$ is toneless, the TA should have been erased by a particular allomorphy rule; on the other hand, if the suffix -o bears the high tone, then the TA should be considered as an attractor of the TA for a reason to be understood.

38 Note, however, that class 5 plurals trigger both 3 rd person F singular and 3 rd person plural agreement on the verb (Puglielli \& Siyaad, 1984:81-85):

(i) class 5 plurals verbal agreement

a. dibidu way cabbayasaa

bulls.the-NOM F-she/they to.drink-PRES-3Pers.-sg-fem

'The bulls drink'

b. dibidu way cabbayaan

bulls.the-NOM F-she/they to.drink-PRES-3Pers.-pl

'The bulls drink'

This suggests that singular agreement is triggered if and only if segmental plural does not

BAALL 5 (2013) 118-159 
(40) Class 5 allomorphy: madáx 'heads' F, pl., ABS

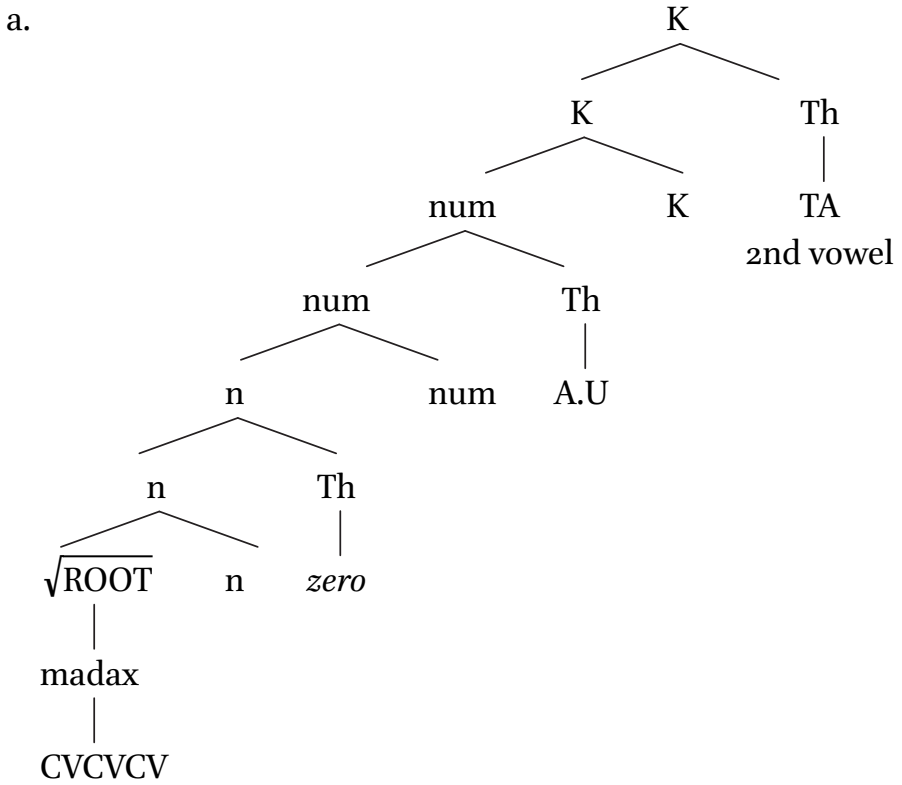

b. V-pos

$\mathrm{TA}$

AT

$\begin{array}{lll}\text { Segments } & \mathrm{m} \text { a d a } \mathrm{x} \\ \text { Template } & \mathrm{C} \text { V C } \underline{\mathrm{V}} \mathrm{C} \mathrm{V}+\mathrm{C} \mathrm{V} \quad \text { [madáx] }\end{array}$

Plural A

$\mathrm{U}$

As a conclusion, the nouns of classes 2 and 5 behave exactly in the same manner with respect to a root lexical template, gender/number/case exponents, and the application of allomorphy rules. Problems (37-a) and (37-b) are settled.

Problem (37-c) concerns the nouns displaying a fixed and predictable template, namely the nouns in class $3 / 4$ (cf. (15) above). As already discussed, this

appear. Note that plural interpretation is not affected by the absence (or delinking) of /A.U/. For reasons of space, we will not look deeper into this intriguing subject. 
template has the shape $\mathrm{CV}_{1}+(\mathrm{CV})+\mathrm{CV}_{2}+\mathrm{CV}_{3}$. I propose to consider that if a root enters the derivation without a skeletal tier in its representation, then the fixed template is inserted by default. ${ }^{39}$ This happens in the n-head, as shown below: ${ }^{40}$

(41) Class 3/4: míis 'table' M sg. ABS

a.

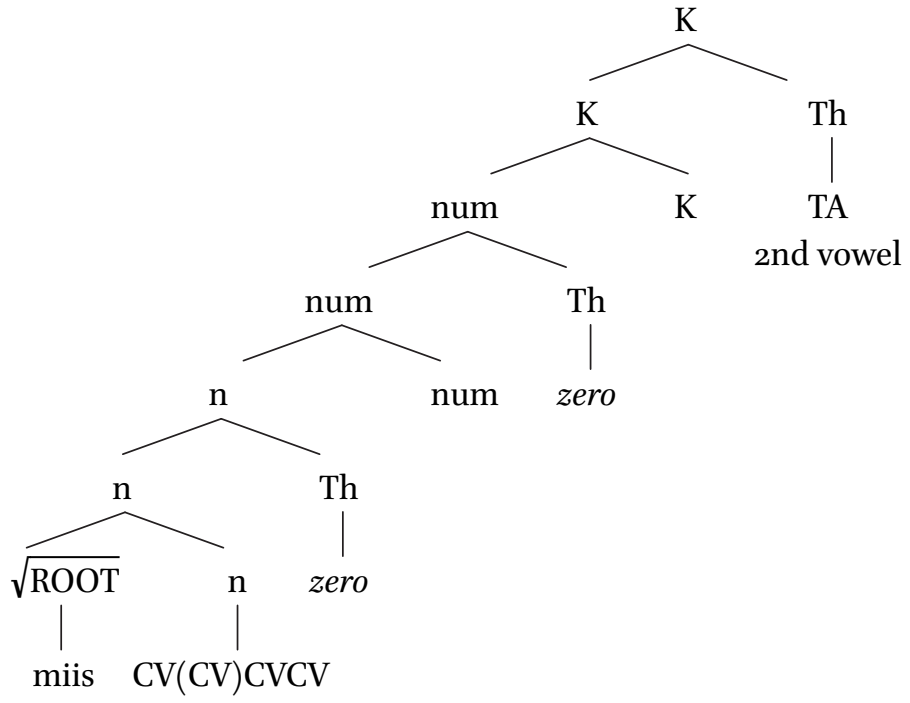

b. V-pos

21

$\mathrm{TA}$

$\mathrm{TA}$

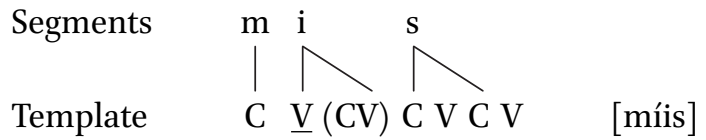

The propagation of the second radical (here $\mathrm{C} 2=/ \mathrm{s} /$ ) is blocked to the right only in the context of the singular, as already noticed. The reason seems to be a constraint on final complex consonantal clusters, which are prohibited in

39 Along with Marantz $(1995,2001)$, the lexical material is introduced below the n-head, whereas predictable material depends on the higher part of the structure.

40 Literature on syntax (cf. Alexiadou et al., 2007 for a review on nominalizations) offers many examples of n-heads introducing nominalizing objects, such as English -ness. The template is such an object.

BAALL 5 (2013) 118-159 
Somali: *CC\#. On the other hand, C2 propagates when the plural suffix /A.U/ is inserted. ${ }^{41}$ The plural is shown below:

(42) Class 3/4: miisás M pl. ABS

a.

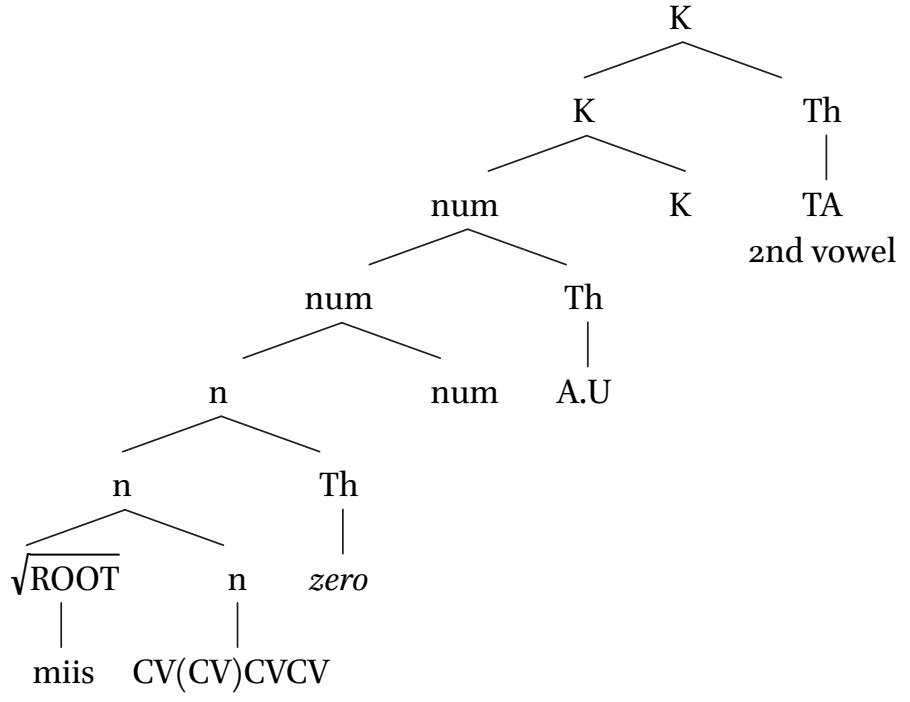

b. V-pos

$2 \quad 1-$

TA

$\mathrm{TA}$

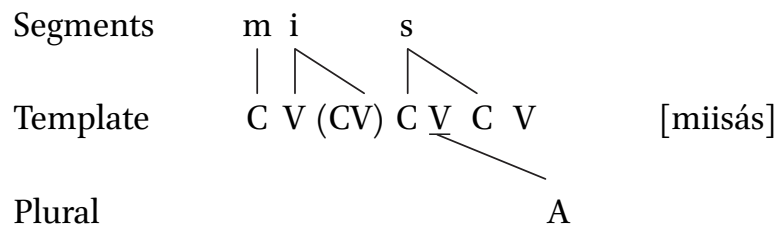

$\mathrm{U}$

The situation depicted above is interesting with respect to AR1 above in (38). Why does this allomorphy rule not apply in class $3 / 4$ ? If this were the case, miisás would be a feminine noun, instead of a masculine one. In fact, the

41 The real question is to understand the reason as to why the plural suffix is infixed between the two consonants, instead of being associated to the last vocalic position. Godon's (1998) solution calls for the antigemination principle, along the lines of McCarthy (1986). Further research is needed on this particular point. 
allomorphy rule in question cannot apply in such a situation as an intervening object appears to be between the root and the plural. Indeed, in order for the ARi (38) to apply, the /A.U/ sequence in the Th-node adjoined to the num-head, must "see" the root. If the template is spelled-out in the n-head, this is not possible. If a noun does not have a lexical template, it requires a default one spelled-out by $n$-head. As a consequence, it is impossible to apply the rule adding a CV in the plural, as the root is not adjacent to the exponent of the plural. This explains why class $3 / 4$ never displays gender polarity. The gender can change only when the root is syntactically adjacent to the plural suffix: in class $3 / 4$ this is not the case, as the fixed template intervenes. Problem (37-c) is accounted for.

Finally, class 1 nouns require a clarification, as they are feminine in the singular, but masculine in the plural. Let us look at the singular first, using the following example: inán 'girl', instead of the usual naág 'woman'. As by hypothesis, feminine gender is marked by the exponent CV. It must be postulated that such an object underlies class 1 singulars, as shown below:

(43) Class 1: inán 'girl', F sg. ABS

a.

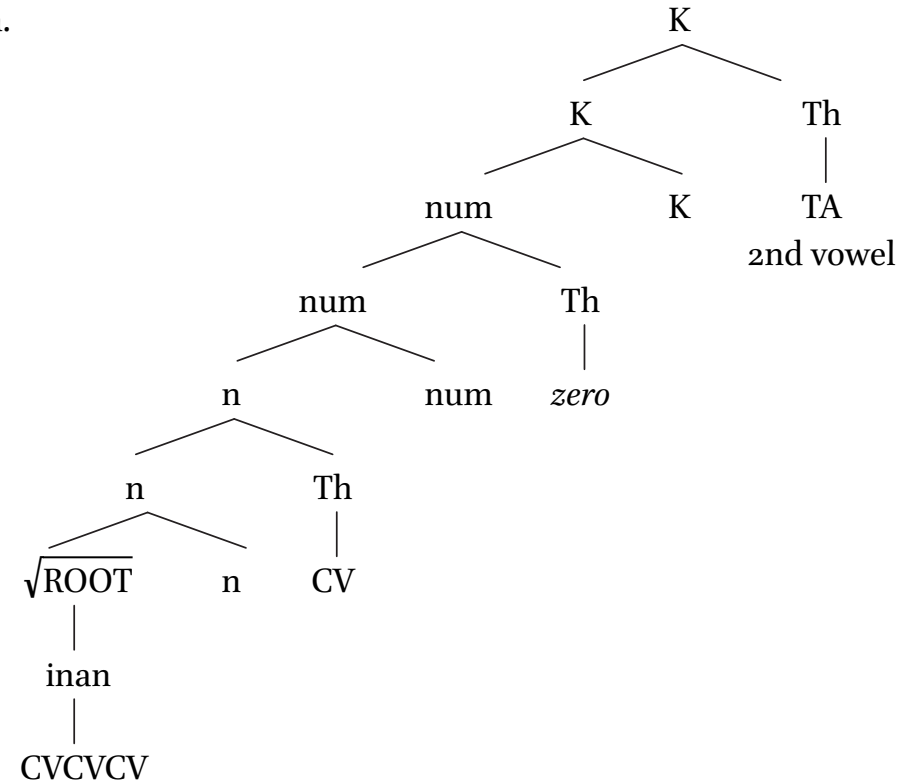

BAALL 5 (2013) 118-159 
b. V-pos

TA

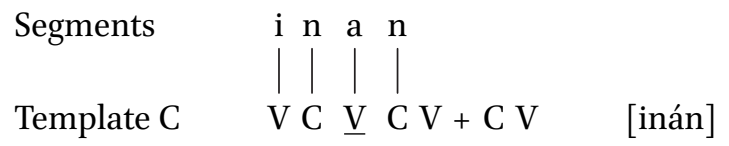

The linearization in (43-b) is correctly predicted by the mechanisms proposed so far. On the other hand, the plural is more problematic. In fact, the allomorphy rule $\mathrm{AR} 1$ (38) cannot be activated, as conditions are not met: the root is not adjacent to the number feature, as a CV intervenes in n-head. Yet, the wrong prediction made by the structure above, is that the plural is feminine. But it is masculine. Therefore, the feminine CV must not be activated in the plural, or it has to be ignored.

One argument supporting such a claim is found in the phonology. The question is whether final $/ \mathrm{n} /$ in inán surfaces in the plural as [m] or as [n]. As already shown in (29), in Somali, underlying $/ \mathrm{m} /$ surfaces as [m] only in intervocalic position, and as [n] when word final. If so, the plural should be [inamó], which it is. However, for this change to be induced, the plural suffix /A.U/ has to be associated to the closest free $\mathrm{V}$ position to the root. Hence, external feminine $\mathrm{CV}$ is ignored, as shown below:

(44) Class 1: inamó 'girls', M sg. ABS

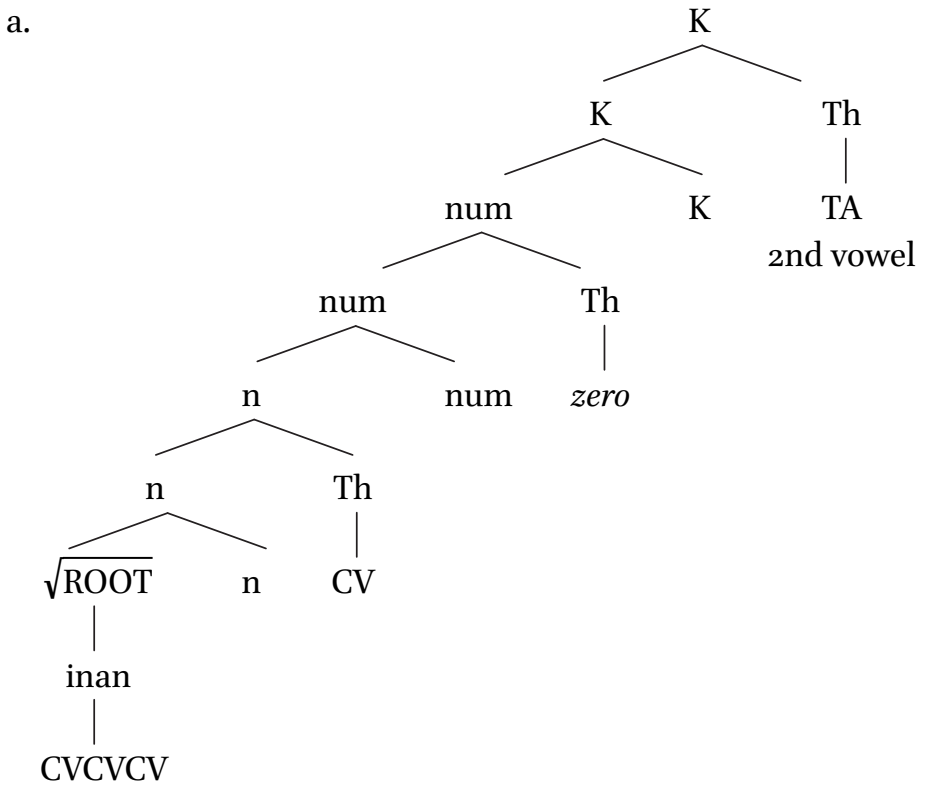

BAALL 5 (2013) 118-159 
b. V-pos

$\mathrm{TA}$

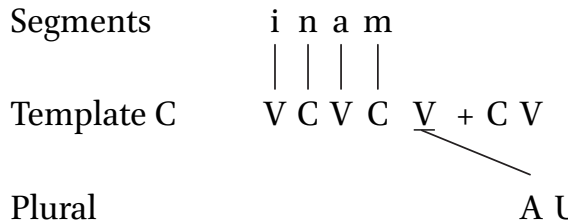

[inamó $]$

A U

Phonological alternations offer us another argument for such a representation. Class 1 has a restricted group of nouns displaying V-zero alternations in V2: galáb vs. galbo 'afternoon(s)', qolóf vs. qolfó 'husk(s)', etc. These cases also suggest that plural $[\mathrm{o}]$ is adjacent to the segments of the root, otherwise the alternation would not be explicable in terms of Government Phonology (Kaye et al., 1985). For the sake of clarity, the linearization of galáb sg. and pl. is given below: ${ }^{42}$

(45) Sg. and pl. of galáb 'afternoon(s)' F sg. ABS

a. V-pos

21

$\mathrm{TA}$

TA

Segments

g a l a b

Template

C V C $\underline{V} \mathrm{C}$ V + C V

[galáb] F sg.

42 These arguments point to the fact that the external feminine CV is not used in plural nouns, otherwise we should expect the gemination in *inammó 'girls' and no alternation in the stem of galáb 'afternoon'. They explain why plurals of declension 1 are masculine, but they do not explain what reason the external CV is not activated for. This problem requires further research.

BAALL 5 (2013) 118-159 
b. V-pos

TA
TA

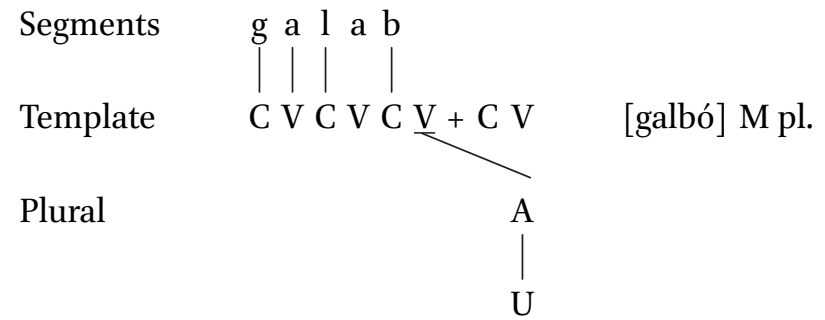

As a conclusion, in class 1 the $[\mathrm{pl}]$ feature overrides the activation of the feminine exponent, i.e. the suffixed CV syllable. This explains why the plural of this class is always masculine. Problem (37-d) is explained.

This mechanism can be applied in deriving not only the ABS case, but also the NOM and the GEN. It is interesting to compare the NOM singular of class 1 to its plural.

Below, the singular of inán 'girl' is represented at NOM:

(46) Class 1 NOM: inani 'girl' sg. F

a.

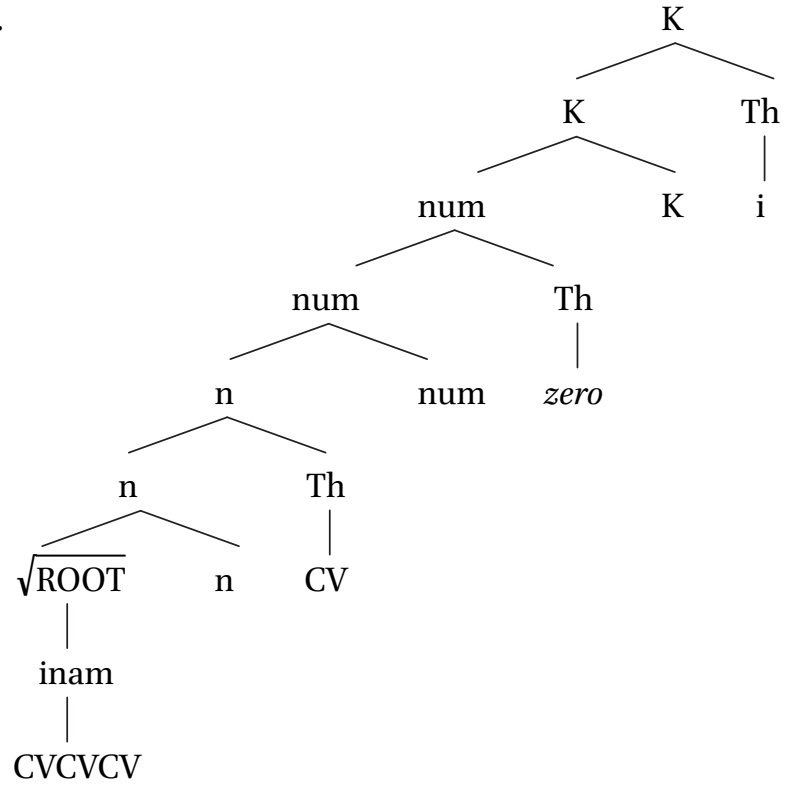


b. NOM

Segments

i n a m

Template

C V C V C V + C V

[inani]

As already shown in (29), floating $-i$ is linked to the external feminine $\mathrm{CV}$, and thus underlying $/ \mathrm{m} /$ surfaces as the final position allophone $[\mathrm{n}]$. On the other hand, plural works as in the ABS, namely the feminine CV is not activated. Indeed, class 1 plurals are masculine in the NOM, too. Only the linearization is shown below, as the structure corresponds to the one in the singular plus the plural suffix /A.U/:

(47) Class 1 NOM: inamo 'girls' sg. M

NOM

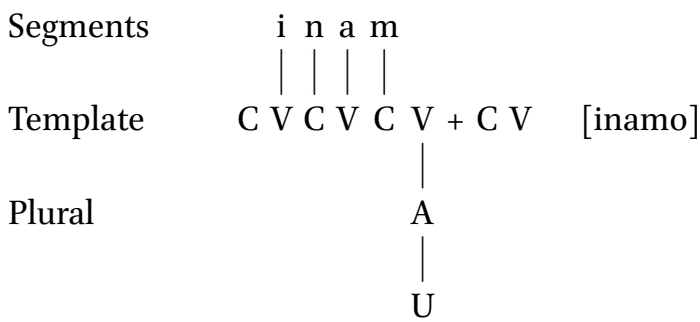

Crucially, if the feminine CV is not exploited by the plural suffix, then the NOM suffix $-i$ does not surface (cf. the ungrammaticality of *inamoi and the well-formedness of madaxi 'heads' F pl. $\left.\mathrm{NOM}^{43}\right)^{4}{ }^{4}$

For reasons of space, we will not explore the structures of other forms.

\section{Conclusion}

The analyses proposed in this paper have shown that a complex nominal system such as the Somali one can be straightforwardly understood assuming a unique marker for each gender, number and case. This consists of the idea

43 Puglielli \& Siyaad (1984:98) clearly say that F nouns ending in a consonant $d o$ take the suffix $-i$ in the NOM, even if their singular is M, as in the case of class 5 .

44 This is an argument for cyclic derivation to apply: the feminine external CV is spelled-out when the lowest part of the structure has already been spelled-out.

BAALL 5 (2013) 118-159 
that the nouns must be decomposed into phonological discrete objects. Each one of these items must correspond to a given morphological property.

The major aim has been to prove that a list of basic ingredients can be finally reached throughout the phonological deconstruction. This analytic path helped us to develop the idea that the so-called "gender polarity" is in fact a secondary effect of the presence of an abstract CV-unit in the representation of feminine nouns.

The CVCV hypothesis was adopted in the representation of each noun. In particular, it was proposed that $\mathrm{CV}$ units can be interpreted as fully independent morphemes. This was demonstrated in the assumed root dichotomy. Roots can either have a lexical template in their representation or not. In the latter case, an independent item is required: this is the fixed sequence $\mathrm{CV}_{1}+(\mathrm{CV})+\mathrm{CV}_{2}+\mathrm{CV}_{3}$. This situation has two advantages. First, it generalizes the syllabic structures of two different classes of nouns ( 3 and 4 ); secondly it relates the presence of the template to a particular inflectional behavior, namely the absence of gender polarity.

To recapitulate, a list of phonological exponents in the sense of DM, along with a few allomorphy rules, trigger the existence, at surface level, of at least five different inflectional classes of nouns. These have traditionally been referred to as declensions by various authors. The approach proposed in the present work, if taken to the extreme, suggests that Somali classes or declensions are not linguistically pertinent, but rather epiphenomenal.

\section{References}

Alexiadou, Artemis, Liliane Haegeman, Melita Stavrou. 2007. Noun phrase in the generative perspective. Berlin: Mouton de Gruyter.

Andrzejewski, Bogumil Witalis. 1964. The Declensions of Somali Nouns. London: School of Oriental and African Studies.

Armstrong, Lilias. 1934. "The phonetic structure of Somali". In: Mitteilungen des Seminars für orientalische Sprachen 37, pp. 116-161.

Banti, Giorgio. 1988. "Two Cushitic Systems: Somali and Oromo". In: Harry van der Hulst, Norval Smith (eds.), Autosegmental studies on pitch accent, Dordrecht: Foris, pp. 11-49.

Barillot, Xavier. 2002. Morphophonologie gabaritique et information consonantique latente en somali et dans les langues est-couchitiques. Ph.D. thesis, Université Paris 7 .

Bendjaballah, Sabrina. 1998. "La palatalisation en somali”. In: Linguistique Africaine 21, pp. $5^{-52}$

. 2003. "The internal structure of the determiner in Beja". In: Jacqueline

BAALL 5 (2013) 118-159 
Lecarme (ed.), Research in Afroasiatic Grammar II. Selected Papers from the Fifth Conference on Afroasiatic Languages, Paris, 200o, Amsterdam/Philadelphia: Benjamins, pp. $35^{-52}$.

Bendjaballah, Sabrina, Martin Haiden. 2008. "A Typology of Emptiness in Templates". In: Jutta Hartmann, Veronika Hegedus, Henk van Riemsdjik (eds.), The Sounds of Silence: Empty Elements in Syntax and Phonology, Amsterdam: Elsevier, pp. 23-52.

Bittner, Maria, Kenneth Hale. 1996. "The structural determination of Case and agreement”. In: Linguistic Inquiry 27, pp. 1-68.

Calabrese, Andrea. 1998. "Some remarks on the Latin case system". In: José Lema, Esthela Treviño (eds.), Theoretical Analyses of Romance Languages. Selected Papers from the 26th Linguistic Symposium on Romance Languages (LSRLXXVI), Mexico City, 28-30 March 1996. Amsterdam/Philadelphia: Benjamins, pp. 71-126.

Embick, David. 2010. Localism versus Globalism in Morphology and Phonology. M.I.T. Press.

Embick, David, Morris Halle. 2005. "The status of stems in Morphological Theory". In: Twan Geerts, Ivo van Ginneken, Haike Jacobs (eds.), Romance Languages and Linguistic Theory, Selected Proceedings from Going Romance 2003, Amsterdam. Amsterdam: John Benjamins, pp. 37-72.

Embick, David, Rolf Noyer. 2007. "Distributed Morphology and the Syntax-Morphology Interface". In: Gillian Ramchand, Charles Reiss (eds.), Oxford Handbook of Linguistic Interfaces, Oxford: Oxford University Press, pp. 289-324.

Frascarelli, Mara, Annarita Puglielli. 2005. "The Focus System in Cushitic Languages”. In: Paolo Fronzaroli, Paolo Marrassini (eds.), Proceedings of the 1oth Hamito-Semitic Congress. Afroasiatic Linguistics. Firenze, pp. 333-358.

. 2007a. "Focus in the Force-Fin System. Information Structure in Cushitic Languages". In: Aboh Enoch, Katharina Hartmann, Malte Zimmermann (eds.), Focus Strategies: Evidence from African languages, Berlin: Mouton de Gruyter, pp. 161-184.

. 2007b. "Focus markers and universal grammar". In: Azeb Amha, Maarten Mous, Graziano Savà (eds.), Omotic and Cushitic Language Studies. Papers from the Fourth Cushitic and Omotic Conference, Leiden 10-12 April, 2003. Köln: Rüdiger Köppe, pp. 169-185.

Godon, Elsa. 1998. "Aspects de la morphologie nominale du somali: la formation du pluriel". Mémoire de DEA, Université Paris VII.

Goldsmith, John. 1978. Autosegmental Phonology. MIT Press.

Guerssel, Mohand, Jean Lowenstamm. 1996. "Ablaut in Classical Arabic Measure I Active Verbal Forms". In:Jacqueline Lecarme, Jean Lowenstamm, Ur Shlonsky (eds.), Studies in Afroasiatic Grammar, Amsterdam/Philadelphia: Benjamins, pp. 123-134.

Halle, Morris. 1992. "The Latvian declension”. In: Gert Booj, Jaap van Marle (eds.), Yearbook of Morphology 1991, Dordrecht: Kluwer Academic, pp. 33-47.

. 1997. "Distributed Morphology: Impoverishment and Fission". In: Benjamin

BAALL 5 (2013) 118-159 
Bruening, Yoonjung Kang, Martha McGinnis (eds.), Papers at the Interface, MIT Press, vol. 30 of MIT Working Papers in Linguistics, pp. 425-449.

Halle, Morris, Alec Marantz. 1993. "Distributed Morphology and the Pieces of Inflection". In: Kenneth Hale, Samuel Jay Keyser (eds.), The View from Building 20, Cambridge, Massachusetts: MIT Press, pp. 111-176.

Halle, Morris, Bert Vaux. 1998. "Theoretical aspects of Indo-European nominal morphology: The nominal declensions of Latin and Armenian”. In: Jay Jasanoff, H. Craig Melchert, Lisi Olivier (eds.), Mir Curad: Studies in Honor of Clavert Watkins, Institut für Sprachwissenschaft der Universität Innsbruck, pp. 223-240.

Hyman, Larry. 1981. "Tonal Accent in Somali”. In: Studies in African Linguistics 12, 2, pp. 169-203.

Kaye, Jonathan. 1990. “'Coda' licensing”. In: Phonology 1, 7, pp. 301-330. . 1995. "Derivations and Interfaces”. In: Jacques Durand, Francis Katamba (eds.), Frontiers of Phonology, London \& New York: Longman, pp. 289-332.

Kaye, Jonathan, Jean Lowenstamm, Jean-Roger Vergnaud. 1985. "The internal structure of phonological elements: a theory of charm and government”. In: Phonology Yearbook 2, pp. 305-328.

1990. "Constituent structure and government in phonology". In: Phonology Yearbook 7, pp. 193-231.

Kihm, Alain. 2010. "Plural formation in Nubi and Arabic". Paper presented at BAAL's First Conference on Afroasiatic Grammar, Université Paris VII, Nov. 25-27 2010.

Le Gac, David. 2001. Structure prosodique de la focalisation: le cas du somali et du français. Ph.D. thesis, Université Paris VII.

Lecarme, Jacqueline. 2002. “Gender 'Polarity': Theoretical Aspects of Somali Nominal Morphology”. In: Paul Boucher (ed.), Many Morphologies, Somerville, Mass.: Cascadilla Press, pp. 109-141.

Lowenstamm, Jean. 1996. "CV as the only syllable type". In: Jacques Durand, Bernard Laks (eds.), Current Trends in Phonology, Manchester: Salford, pp. 419-441.

. 2008. "On little $n, \sqrt{ }$ and types of nouns". In: Jutta Hartmann, Veronika Hegedus, Henk van Riemsdjik (eds.), The Sounds of Silence: Empty Elements in Syntax and Phonology, Amsterdam: Elsevier, pp. 105-143.

. To appear. "Derivation by Phase and Affixes as Roots". In: Artemis Alexiadou, Hagit Borer, Florian Schäfer (eds.), The Roots of Syntax and the Syntax of Roots, Oxford: Oxford University Press.

Marantz, Alec. 1995. “Cat as a Phrasal Idiom”. Ms., M.I.T. . 1997. "No escape from syntax: don't try morphological analysis in the privacy of your own Lexicon". In: Alexis Dimitriadis, Laura Siegel, Clarissa Surek-Clark, Alexander Williams (eds.), Proceedings of the 21st Annual Penn Linguistics Colloquium. vol. 4 of University of Pennsylvania Working Papers in Linguistics, pp. 201-225. . 2001. "Words and Things". Ms. M.I.T. 
. 2008. "Phases and Words". In:S.-H. Choe (ed.), Phases in the theory of grammar. Dong In, University of Seoul, pp. 201-225.

McCarthy, John J. 1981. “A Prosodic Theory of Nonconcatenative Morphology”. In: Linguistic Inquiry 12, pp. 373-418.

. 1986. "OCP effects: Gemination and antigemination”. In: Linguistic Inquiry 17, pp. 207-263.

Oltra-Massuet, Isabel. 2000. "On the Constituent Structure of Catalan Verbs". In: M.I.T. Working Papers in Linguistics 33, pp. 279-322.

Oomen, Antoinette. 1981. "Gender and plurality in Rendille". In: Afroasiatic Linguistics $8,1-4$, pp. 35-75.

Orwin, Martin. 1995. Colloquial Somali: A Complete Language Course. Routledge.

Puglielli, Annarita, Mohamed Siyaad. 1984. "La flessione del nome". In: Annarita Puglielli (ed.), Studi Somali 5: Aspetti morfologici lessicali e della focalizzazione, Roma: Min. Affari Esteri, Dir. Generale per la Cooperazione allo Sviluppo, pp. 53112.

Saeed, John Ibrahim. 1993. Somali Reference Grammar. Kesington, Maryland: Dunwoody Press.

1999. Somali. Amsterdam/Philadelphia: John Benjamins.

Scheer, Tobias. 2004. A Lateral Theory of Phonology, vol. 1: What is CVCV, and why it should be? Berlin/New York: Mouton.

. 2010. "What the initial CV is initial of". Paper presented at the 8th "Rencontres du Réseau Français de Phonologie", Orléans July 1-3, 2010.

BAALL 5 (2013) 118-159 